\title{
Flood Detection and Susceptibility Mapping Using Sentinel-1 Time Series, Alternating Decision Trees, and Bag-ADTree Models
}

\author{
Ayub Mohammadi $\left(\mathbb{D},{ }^{1}\right.$ Khalil Valizadeh Kamran, ${ }^{1}$ Sadra Karimzadeh $\left(\mathbb{D},{ }^{1,2,3}\right.$ \\ Himan Shahabi $\mathbb{D}^{4,5}$ and Nadhir Al-Ansari $\mathbb{D}^{6}$ \\ ${ }^{1}$ Department of Remote Sensing and GIS, University of Tabriz, Tabriz 5166616471, Iran \\ ${ }^{2}$ Institute of Environment, University of Tabriz, Tabriz 5166616471, Iran \\ ${ }^{3}$ Department of Architecture and Building Engineering, Tokyo Institute of Technology, Yokohama 226-8502, Japan \\ ${ }^{4}$ Department of Geomorphology, Faculty of Natural Resources, University of Kurdistan, Sanandaj 66177-15175, Iran \\ ${ }^{5}$ Department of Zrebar Lake Environmental Research, Kurdistan Studies Institute, University of Kurdistan, \\ Sanandaj 66177-15175, Iran \\ ${ }^{6}$ Department of Civil, Environmental and Natural Resources Engineering, Lulea University of Technology, Lulea 971 87, Sweden
}

Correspondence should be addressed to Ayub Mohammadi; mohammadi.ayub@tabrizu.ac.ir and

Nadhir Al-Ansari; nadhir.alansari@ltu.se

Received 6 June 2020; Revised 13 October 2020; Accepted 24 October 2020; Published 17 November 2020

Academic Editor: Dan Selişteanu

Copyright $\odot 2020$ Ayub Mohammadi et al. This is an open access article distributed under the Creative Commons Attribution License, which permits unrestricted use, distribution, and reproduction in any medium, provided the original work is properly cited.

Flooding is one of the most damaging natural hazards globally. During the past three years, floods have claimed hundreds of lives and millions of dollars of damage in Iran. In this study, we detected flood locations and mapped areas susceptible to floods using time series satellite data analysis as well as a new model of bagging ensemble-based alternating decision trees, namely, bag-ADTree. We used Sentinel-1 data for flood detection and time series analysis. We employed twelve conditioning parameters of elevation, normalized difference's vegetation index, slope, topographic wetness index, aspect, curvature, stream power index, lithology, drainage density, proximities to river, soil type, and rainfall for mapping areas susceptible to floods. ADTree and bag-ADTree models were used for flood susceptibility mapping. We used software of Sentinel application platform, Waikato Environment for Knowledge Analysis, ArcGIS, and Statistical Package for the Social Sciences for preprocessing, processing, and postprocessing of the data. We extracted 199 locations as flooded areas, which were tested using a global positioning system to ensure that flooded areas were detected correctly. Root mean square error, accuracy, and the area under the ROC curve were used to validate the models. Findings showed that root mean square error was 0.31 and 0.3 for ADTree and bag-ADTree techniques, respectively. More findings illustrated that accuracy was obtained as 86.61 for bag-ADTree model, while it was 85.44 for ADTree method. Based on AUC, success and prediction rates were 0.736 and 0.786 for bag-ADTree algorithm, in order, while these proportions were 0.714 and 0.784 for ADTree. This study can be a good source of information for crisis management in the study area.

\section{Introduction}

Natural disasters such as tornadoes, floods, volcanic eruptions, hurricanes, tsunamis, and earthquakes occur across the globe $[1,2]$, with associated loss of life and damage to economies $[1,3]$. Flooding is one of the natural hazards with the highest impact and social, economic, and environmental consequences, especially for cities and agricultural lands [4].
During the past three years, different parts of Iran have been devastated by floods which claimed hundreds of lives and millions of dollars of damage to properties $[5,6]$. Thus, comprehensive flood assessment and management are essential to downgrade floods' effects on human lives and livelihoods [7-9].

Typically, floods occur when rivers overflow over the banks after a heavy rainfall. Floods lead to economic, 
environmental, and social problems, such as damage to roads, farms, and infrastructures, and sometimes pollute surface water resources via the transfer of industrial waste $[10,11]$, which itself creates many health problems. Flash floods claim about 20,000 lives annually [12], and, from 1995 till today, approximately 110 million people have been affected by the floods' damage $[10,13,14]$. During the last 50 years, there were 2400 severe floods in Iran, which resulted in the homelessness of a large number of people and serious financial damage of about 200 million USD [15]. Iran is a country with arid and semiarid climate that is prone to destructive floods [5].

In the last three years, almost all provinces of the country have been affected by floods [6]. One of the most recent and destructive floods happened in Sistan and Baluchestan Province in January 2020. The factors contributing to the extent of damage were heavy rainfall, poor watershed management, farming on river banks, and poor flood warning systems [5]. Flood susceptibility mapping (FSM) is an essential management way to identify areas at risk and also to prevent licensed and unlicensed construction in highrisk areas [1]. Due to superficial assessment, maps generated for the floods in Sistan and Baluchestan Province have not been suitable for crisis flood management. Our aim with this research is to improve flood detection and susceptibility mapping to aid flood managers and minimize loss to life and property.

During the past decades, remote sensing (RS) and Geographic Information Systems (GIS) have opened up new opportunities to create and assess large datasets to extract more accurate and valuable flood hazard maps $[5,12,16]$. Synthetic Aperture Radar (SAR) can collect data, day or night, penetrate through clouds, and is both air- and spacebased $[17,18]$. European Space Agency (ESA) has provided researchers with free and comprehensive data of Sentinel for variety of purposes. In this study, Sentinel-1 was applied for floods analysis. Hybrid algorithms are now more reliable than the single models $[5,19]$, because the ensemble is used to increase the prediction accuracy of a single classifier [5, 20, 21]. Researchers tend to apply machine learning ensemble models that are better suited for sophisticated flood assessment. They have improved flood prediction $[1,2,4,5,10,22-24]$. It is worth mentioning that there is not a universally accepted model yet, which has been known to be superior among all [5]. In this study, we use ADT and bagging ensemble based alternating decision trees (bagADT) models for mapping areas susceptible to floods.

Many models have been developed and utilized for flood studies by researchers worldwide, such as bivariate models of frequency ratio [21, 25-28], analytic network process [29-31], logistic regression $[11,32]$, support vector machine model $[24,33,34]$, random forest [35], adaptive neurofuzzy inference system [9, 36-39], imperialistic competitive algorithm [40], weight of evidence [24], LogitBoost alternating decision trees [41, 42], bagging ensemble based on K-nearest neighbor classifier $[1,5,43]$, reduced-error pruning trees with bagging and random subspace ensembles [1], Multicriteria DecisionMaking (MCDM) analysis [19, 44-47], analytical hierarchy process [48, 49], and the evidential belief function [50].
Unfortunately, many flood susceptibility models have limitations in performance, meaning that they do not involve nonflooded locations and generally consider only class weights instead of weights for layers [5, 51]. Additionally, MCDM models generate bias and errors that are based on experts' opinions [5]. At the same time, flooding at a county scale is a complex and a nonlinear process, which cannot be predicted and mapped using these simple techniques.

Our study has two main purposes: (1) to present a new ensemble approach of bag-ADTree for mapping areas prone to flooding, which has rarely been applied for FSM, either locally or globally, and (2) to map flooded areas using time series analysis of Sentinel-1 data, which has not yet been applied in Iran.

\section{Description of the Study Area}

From 10 to 12 January 2020 (for three days), a very destructive flood occurred in Sistan and Baluchestan Province, southeast of Iran (Figure 1). We selected Fanuj County (1835 $\mathrm{km} 2$ ) for our study area as it was heavily impacted by flooding. Fanuj is one of the oldest cities in the southwest of Sistan and Baluchestan Province. It is located $180 \mathrm{~km}$ south of Iranshahr city and $550 \mathrm{~km}$ from Zahedan city (the capital of Sistan and Baluchestan Province). The study area is located at $26^{\circ} 34^{\prime} 33^{\prime \prime} \mathrm{N} 59^{\circ} 38^{\prime} 23^{\prime \prime} \mathrm{E}$ and is 185 meters above sea level [52]. This study area was selected for two reasons: (1) based on the local and government reports, the selected study area has experienced most of the damage, and (2) it is located in the southern part of the province and the upper-hand water pours to the study area. It has a warm and dry climate with relatively low humidity and an annual rainfall of about $550 \mathrm{~mm}$ [53]. Khermat, Katich, Ramak, Zavar, Kaskan, Megoon, Pir Sehran, Fenuj Gorge, Muskotan, and Modanche are the most important rivers within the study area $[15,54]$. Much of the arid landscape is poor rangeland. It is rocky with frequent rock outcrops and entisol and aridisol soil types. Bedrock is predominantly Eocene flysch in general (composed of shale, marl, sandstone, conglomerate, and limestone). This arid landscape is prone to flash floods. Figure 2 shows the extent of the 2020 flooding in the study area.

\section{Materials and Methods}

3.1. Data Acquisition. We used Sentinel-1 data (collected from scihub.copernicus.eu) for flood inventory and time series analysis of the study area. A $30 \mathrm{~m}$ spatial resolution Digital Elevation Model (DEM) was collected from United States Geological Survey (USGS) website and used for extracting a variety of layers, such as slope, aspect, elevation, stream power index (SPI), topographic wetness index (TWI), curvature, proximity to the river, and river density (rivers networks were extracted using hydrology toolbox in GIS). Geology and soil maps were acquired from Geological Organization of Iran and applied to digitize the geology and soil type layers. Rainfall data was obtained from Tropical Rainfall Measuring Mission (TRMM) and, finally, Normalized Differences Vegetation Index (NDVI) was extracted from Sentinel-2 data. 

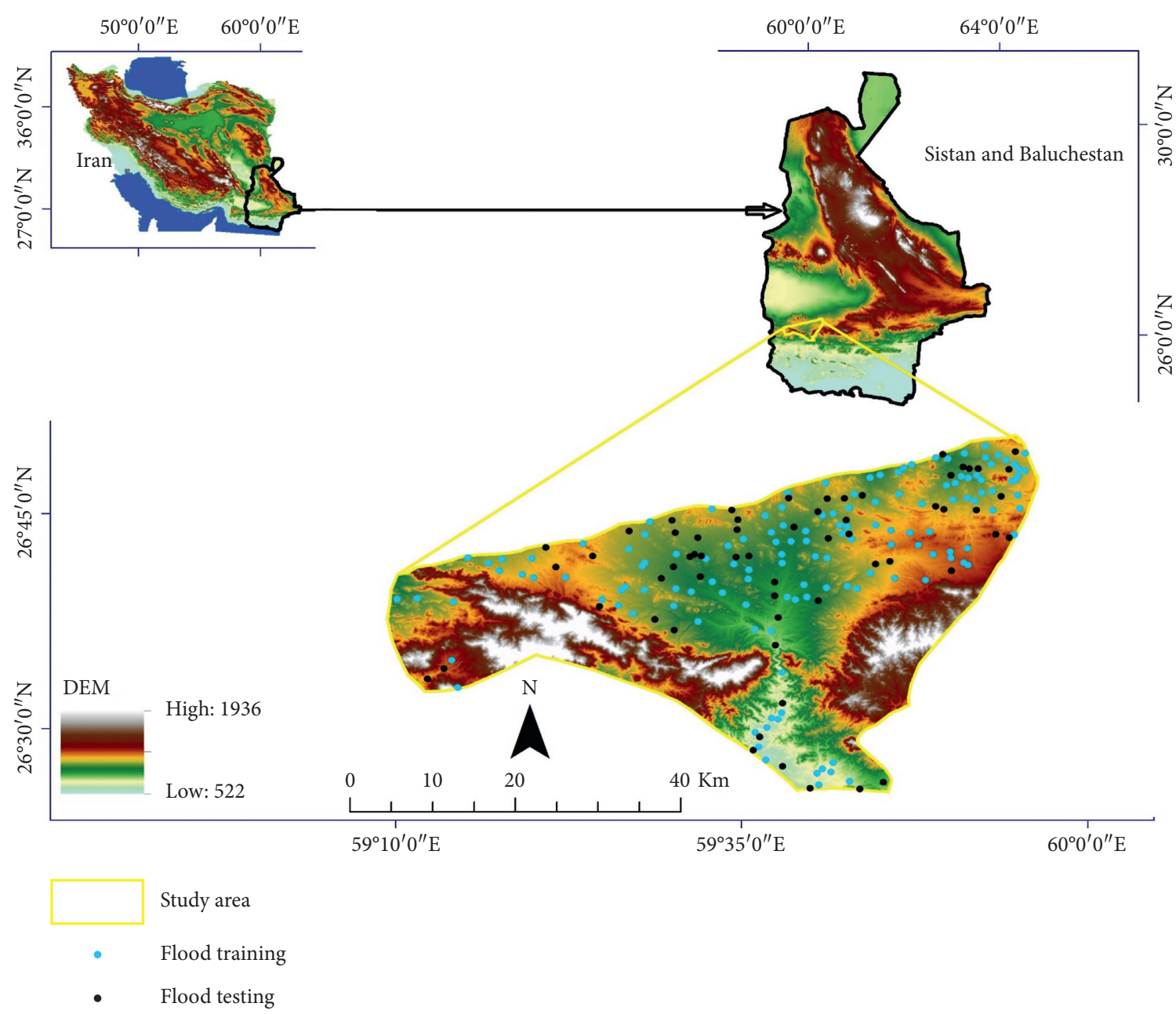

Figure 1: Location of the study area.

Figure 3 shows the methodology we used in this study step by step. The workflow consists of the following: (1) data collection and preparation (containing appropriate conditioning factors, satellite data for flood detection, and time series assessment), (2) extraction of a flood inventory map, (3) modelling flood susceptibility by using ADT and bagADT algorithms as well as time series analysis, and finally (4) accuracy assessment and comparison of the models. A pair of Sentinel-1 satellite data was employed for flood detection. The flood inventory was randomly divided into two groups of $70 \%$ (for training the models) and 30\% (to validate the algorithms). Moreover, twelve Sentinel-1 scenes were acquired and used for extracting the area of water in the flooded regions of the study area. ADT and bagADT models were employed for flood susceptibility analysis in the study area. A set of statistical methods, including RMSE, overall accuracy, and receiver operating characteristic (ROC) curve, were utilized for validation purposes.

3.2. Selection of the Best Factors for Flood Modelling. In order to obtain a better finding, spatial association for all factors should be met [34]. Eliminating null factors from the algorithms can enhance the prediction power of the methods
$[46,55,56]$. The Latent Semantic Analysis (LSA) technique using Waikato Environment for Knowledge Analysis (WEKA 3.6.9) software was applied for selection of the most effective factors in the study area. It is worth mentioning that our criteria were the other study and geographical situation of the study.

3.3. Flood Conditioning Factors. In order to run a model, a set of conditioning and triggering parameters must be collected and applied $[5,34,57]$. It is generally accepted that the magnitude of a flood depends greatly on rainfall intensity and duration [46]. Other factors, including topography, geology, vegetation, and soil types, can have also considerable effects on flooding. In this study, twelve conditioning and triggering parameters (related to the geoenvironmental characteristics of the study area) were initially selected for flood susceptibility assessment. These factors are slope, elevation, aspect, curvature, SPI, TWI, lithology, rainfall, NDVI, river density, proximity to river, and soil type.

It is clear that the higher slopes increase surface runoff and water velocity $[5,58]$; conversely, lower slopes mean greater flood depths $[5,56]$. In this study, the slope layer was created from the SRTM DEM (Figure 4(a)). Relative 


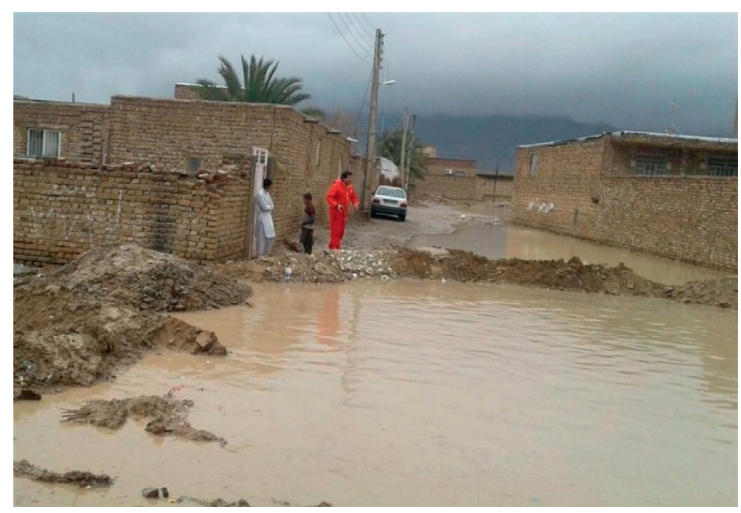

(a)

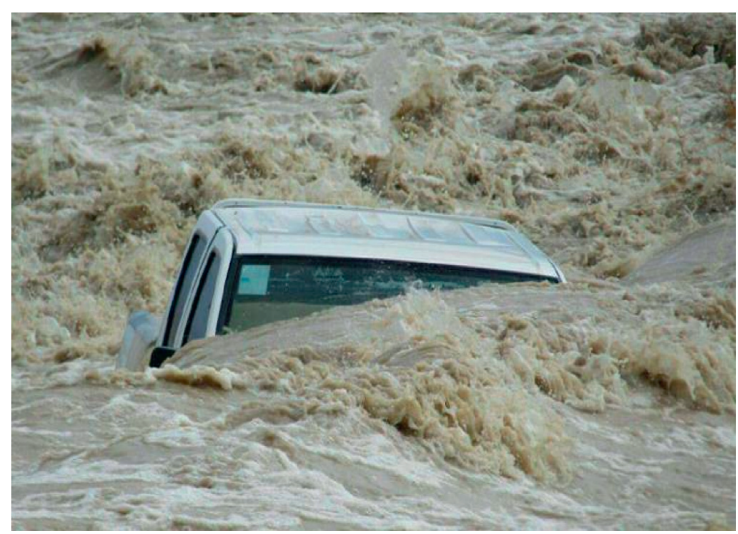

(c)

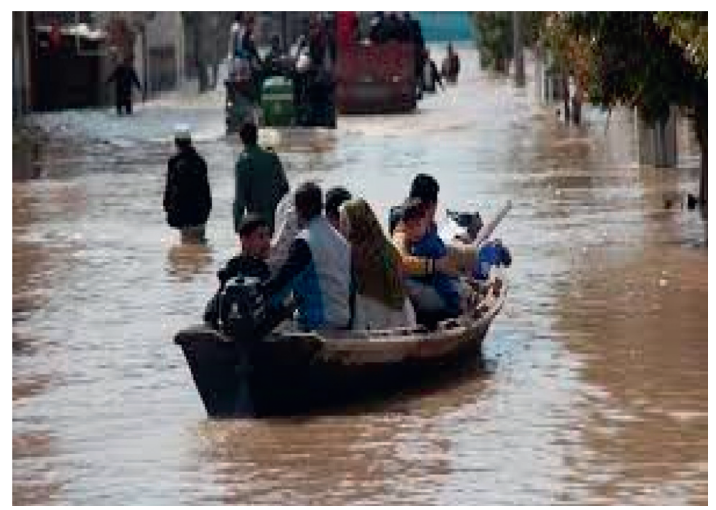

(b)

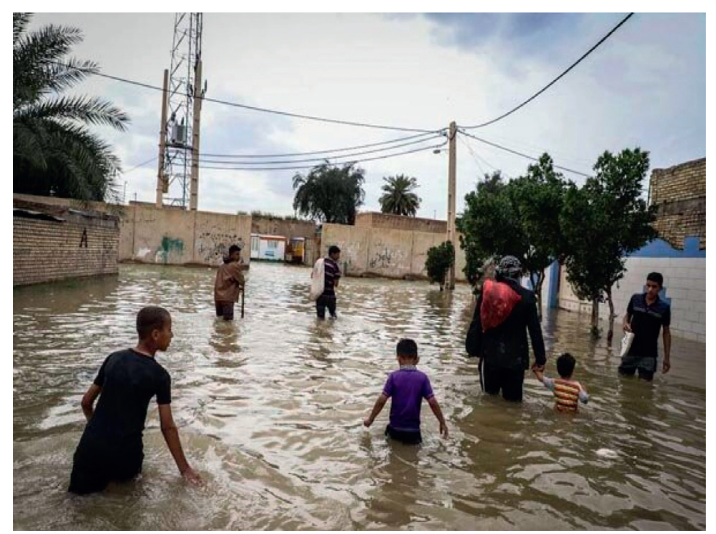

(d)

Figure 2: Photos of flood damage to Sistan and Baluchestan, Iran.

elevation is obviously an important factor in flood analysis as lower elevations have a greater potential for runoff and flooding [56], while the higher areas are above flood levels [5]. Figure 4(b) shows elevation factor for the current study. Aspect was selected as one of the factors for modelling the algorithms, because it is related to the directions and convergence of water flow [59]. For this study, we categorized the aspect map into nine classes (Figure 4(c)). Stream flow is normally affected by curvature [60]. Based on other studies, curvature with value of zero has been almost more potential for flooding than the positive or negative values $[5,11,56]$ (Figure 4(d)).

SPI refers to the erosive ability and power of water in rivers, which is calculated by the following equation [60-63]:

$$
\mathrm{SPI}=(\alpha \times \tan \beta),
$$

where $\alpha$ is flow accumulation of streams in an area and $\beta$ is the slope. Generally, sediments relocating and river bank erosion are among the most noticeable issues related to SPI, where the high SPI rates lead to extreme channel transformation $[64,65]$. Therefore, more SPI values will boost flooding rates (Figure 5(a)). TWI (Figure 5(b)) is an important factor in flood susceptibility analysis, which is a way to calculate accumulation of water at any location under the influence of gravitational force $[65,66]$. It highlights soil moisture patterns [67]. TWI is measured through the following equation [65]:

$$
\mathrm{TWI}=\operatorname{In}\left(\frac{\alpha}{\tan \beta+c}\right),
$$

where $\alpha$ is flow accumulation of streams, $\beta$ is the slope of an area, and $c$ is 0.001 .

Variations in permeability of rocks and sediments may influence water flow $[4,65]$. We digitized the lithology layer in a GIS environment using the geology map (Figure 5(c)). The role of rainfall on flooding is a significant factor for flood susceptibility analysis [55]. Rainfall layer was extracted from TRMM data for recent five years from early 2015 to late 2019. We used Inverse Distance Weighted (IDW) method in a GIS environment to create the rainfall layer (Figure 5(d)).

NDVI can provide a good indication for flood potential [5] as vegetation can control runoff [68]. We extracted NDVI for the study area from Sentinel-2 data using the following formula (Figure 6(a)):

$$
\text { NDVI }=\frac{(\text { NIR }- \text { RED })}{(\text { NIR }+ \text { RED })}
$$

River density refers to the quantity of streams in a specific area $[5,62]$. Therefore, high river density has a greater potential for flooding and vice versa [10] (Figure 6(b)). Proximity to river plays a major role in magnitude and distribution of floods $[1,59,69]$. The longer the distance, the lower the probability of flooding [70], and, because of the lower infiltration rates in the study area, rapid 


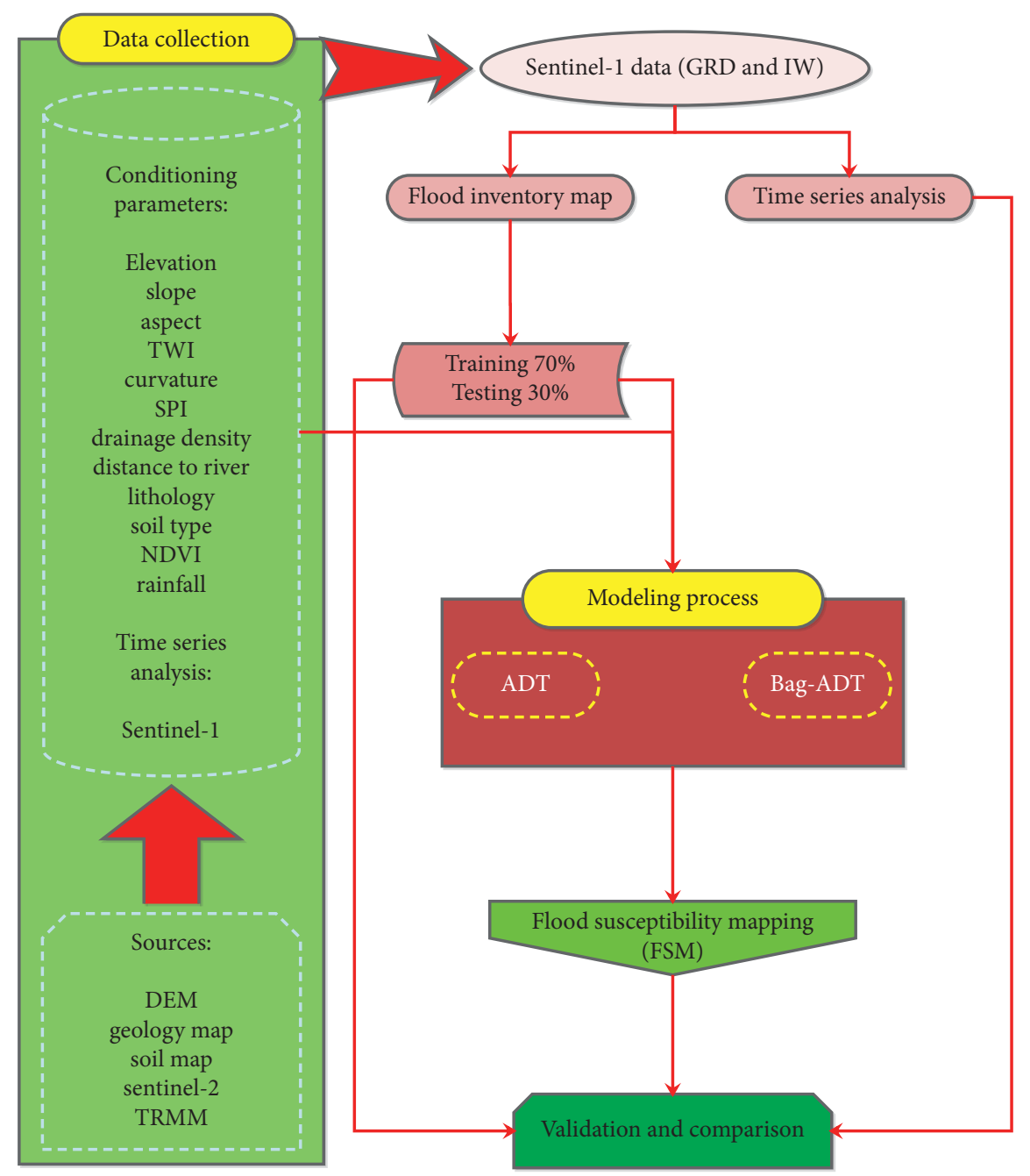

Figure 3: Methodology of the study.

runoff occurs (Figure 6(c)). Regarding infiltration and runoff, soil type has to be considered in flood susceptibility assessment $[46,61,67]$. The soil layer was digitized from soil map of the study area. The layer has three groups of rock outcrops/entisols, rocky lands, and entisols/aridisols (Figure 6(d)).

Classification of geoenvironmental factors must be carried out for flood susceptibility assessment $[11,71]$. Based on the mechanism of flooding in the study area, a set of twelve conditioning and triggering parameters were finally taken into account. The floods-affecting factors were classified into different classes (Table 1). This classification is based on the susceptibility assessment of each factor to flood occurrences.

3.4. Flood Inventory Using Sentinel-1 Data. Sentinel-1 (Cband and $5.7 \mathrm{~cm}$ wavelength) is the first satellite program of the European Space Agency (ESA) which consists of two satellites of Sentinel-1A and Sentinel-1B [57, 72]. It has Synthetic Aperture Radar (SAR) instrument that acquires data in all weather conditions, day and night $[5,57,72,73]$. Sentinel-1 has three product types: (1) Ground Range
Detected (GRD), (2) Single-Look Complex (SLC), and (3) Ocean [72]. Strip Map (SM), Wave (WV), Interferometric Wide (IW) Swath, and Extra Wide (EW) Swath are four sensor modes for the satellite with different applications and spatial resolutions [57]. The main negative point for the C-bands satellite missions is that they cannot penetrate into dense vegetation coverage $[5,72,74]$. Sentinel missions are available online freely (scihub.copernicus.eu and vertex. daac.asf.alaska.edu). In this study, we used Sentinel-1 (GRD and IW) data for flood detection (Table 2).

3.4.1. Data Preprocessing, Processing, and Postprocessing. Inventory maps play an important role in flood susceptibility studies [11, 29,59]. A pair of Sentinel-1 (GRD and IW) data for the dates of 31/12/2019 and 12/01/2020 were acquired to identify and detect flood locations in the study area. Using Sentinel Application Platform (SNAP 7.0) and ArcGIS 10.5, the data were preprocessed and processed, respectively. First of all, using SNAP software, the data were clipped as the study area and the orbit files of them were updated successfully and then were calibrated to optimize extracted information. Normally, there is speckle in raw 


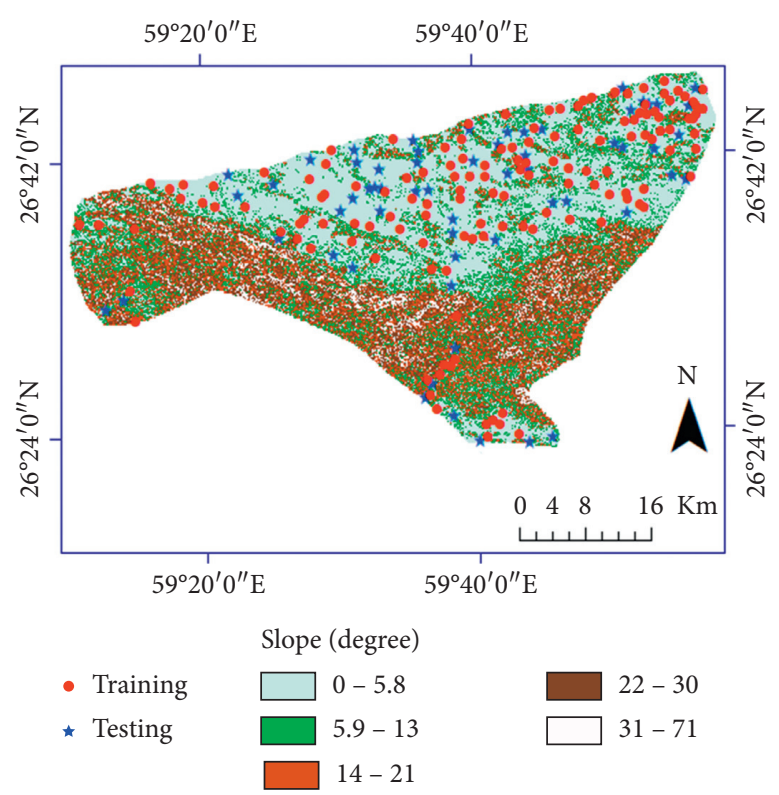

(a)

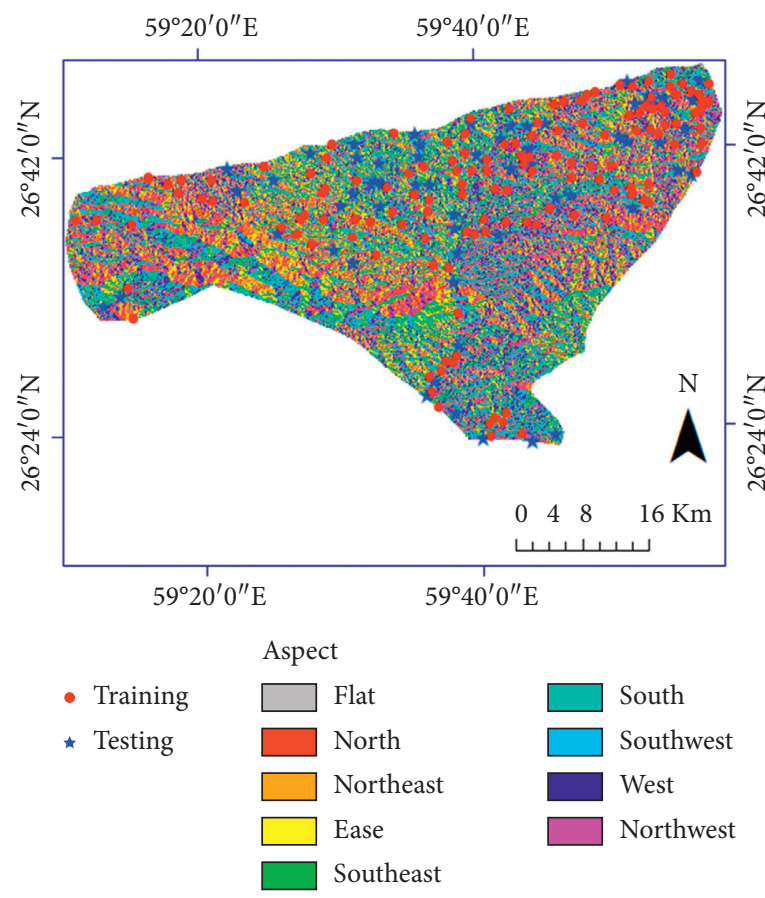

(c)

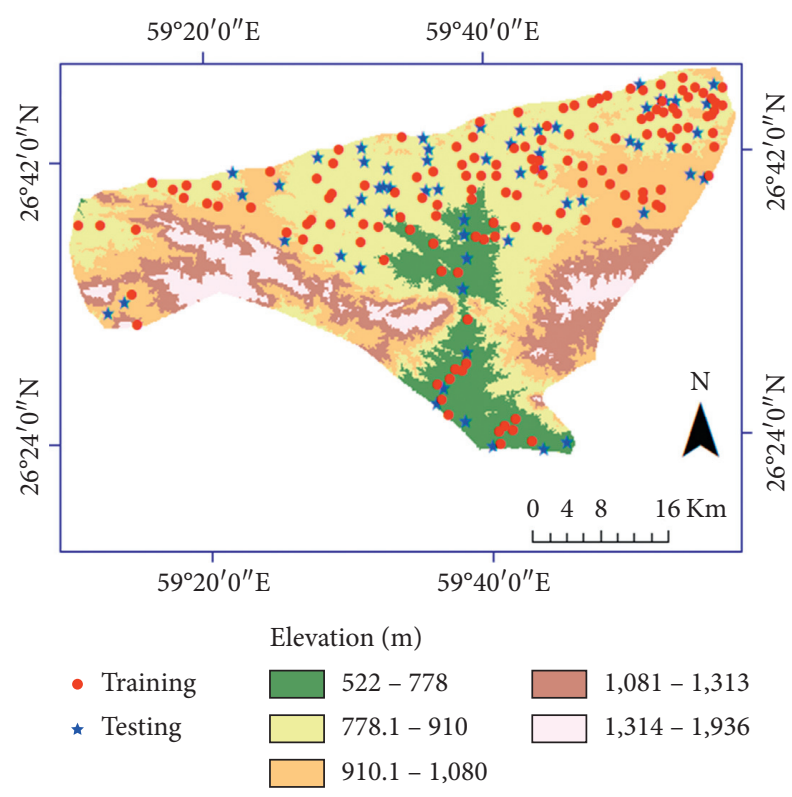

(b)

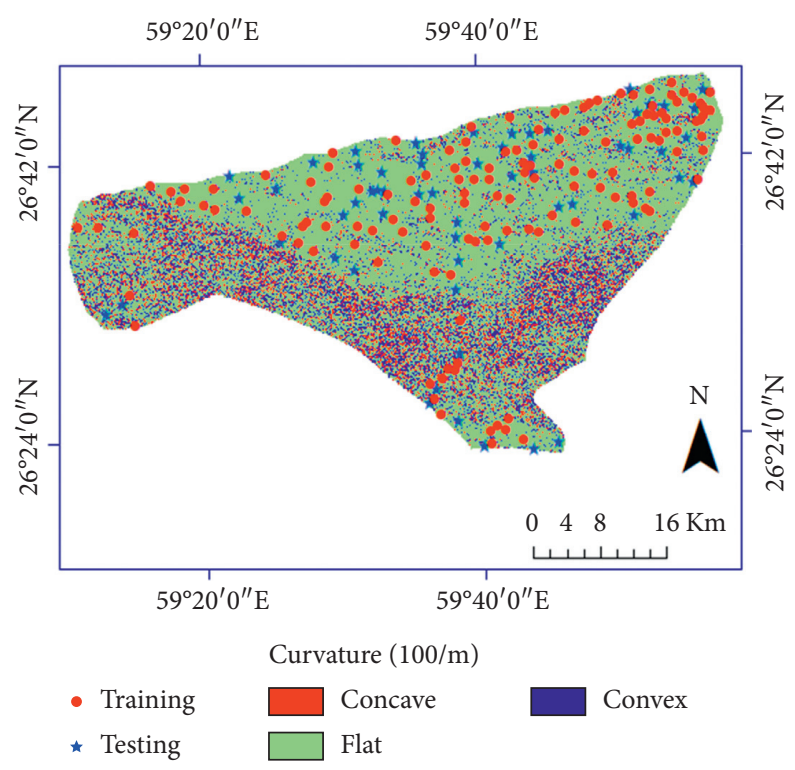

Figure 4: (a) slope. (b) Elevation. (c) Aspect. (d) Curvature.

satellite data. Therefore, they were smoothed using speckle filtering command in SNAP. In order to remove distortions from data, such as layover, shadow, and foreshortening as well as georeferencing, terrain correction module was employed. To extract maximum ratio of information, we created a dB band for both imageries. Finally, we stacked the data for further processing into ArcGIS. ArcGIS is able to clip data as basin borders exactly, so all bands (one by one) were clipped as the study area and used for RGB creation. $\mathrm{dB}$ band of before an event was utilized for red window, while the $\mathrm{dB}$ band of after event image was used for green and blue windows. By using this model, flooded areas can be easily identified and recorded, because using this technique flooded areas can even be differentiated from constant water bodies. Therefore, red areas (showing flooded areas) were digitized as flood prone areas. Then they were digitized in point format; these points were divided into training $80 \%$ and testing 20\%. A total of 199 locations were extracted as flood susceptible regions. Using a handheld Global Positioning System (GPS), 20\% (40 locations) of the detected flood locations were well validated in the study area (Figure 7). 


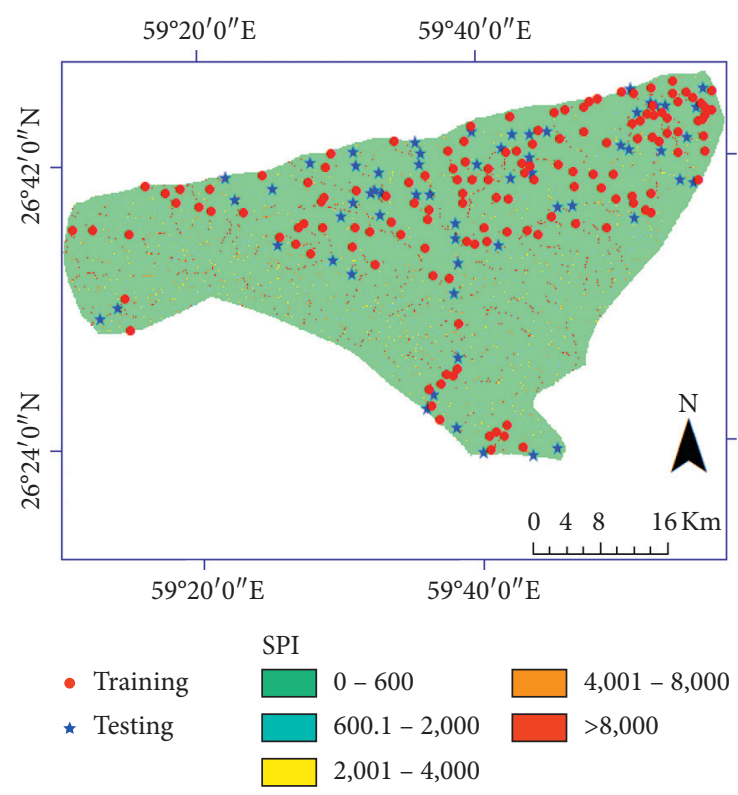

(a)

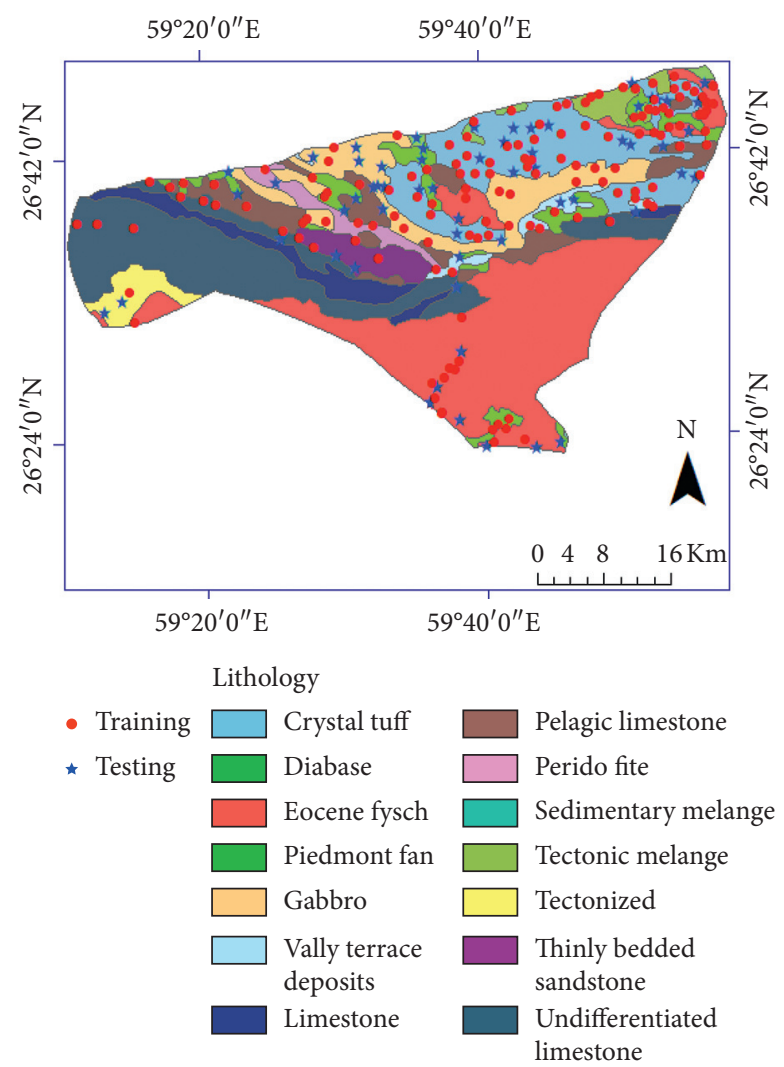

(c)

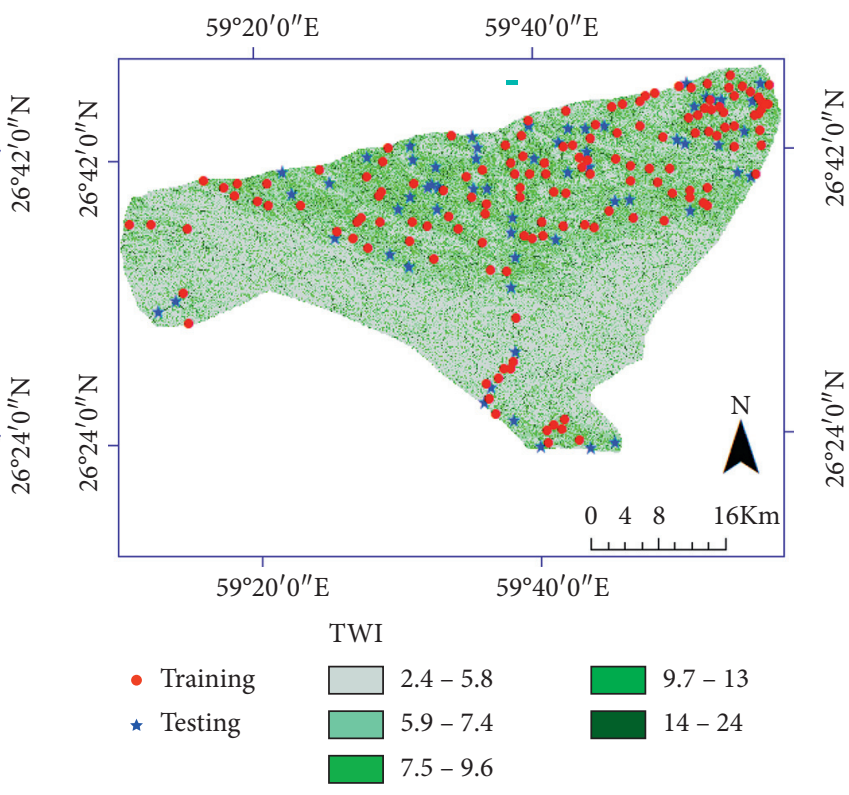

(b)

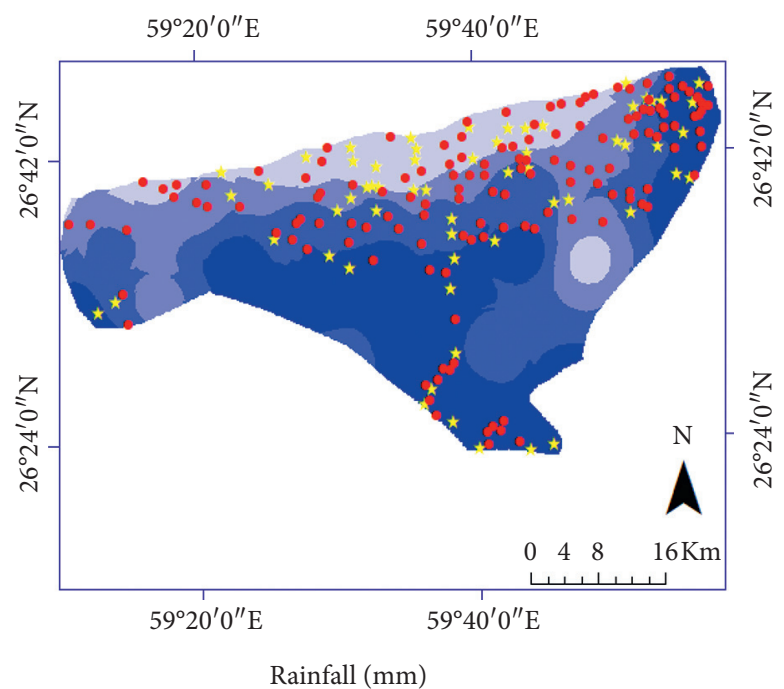

(d)

Figure 5: (a) SPI. (b) TWI. (c) Lithology. (d) Rainfall. 


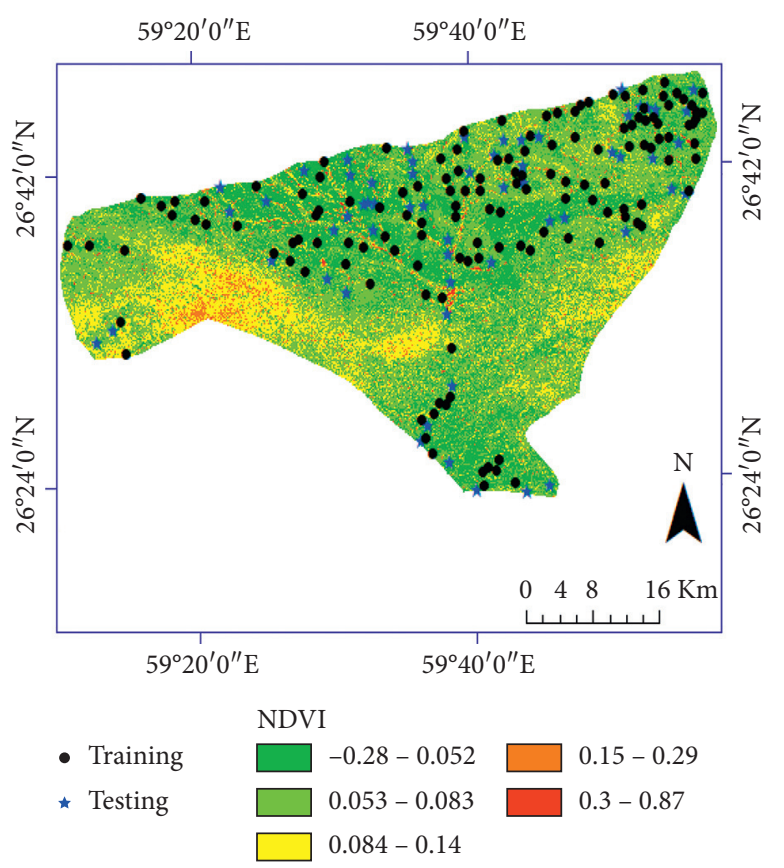

(a)

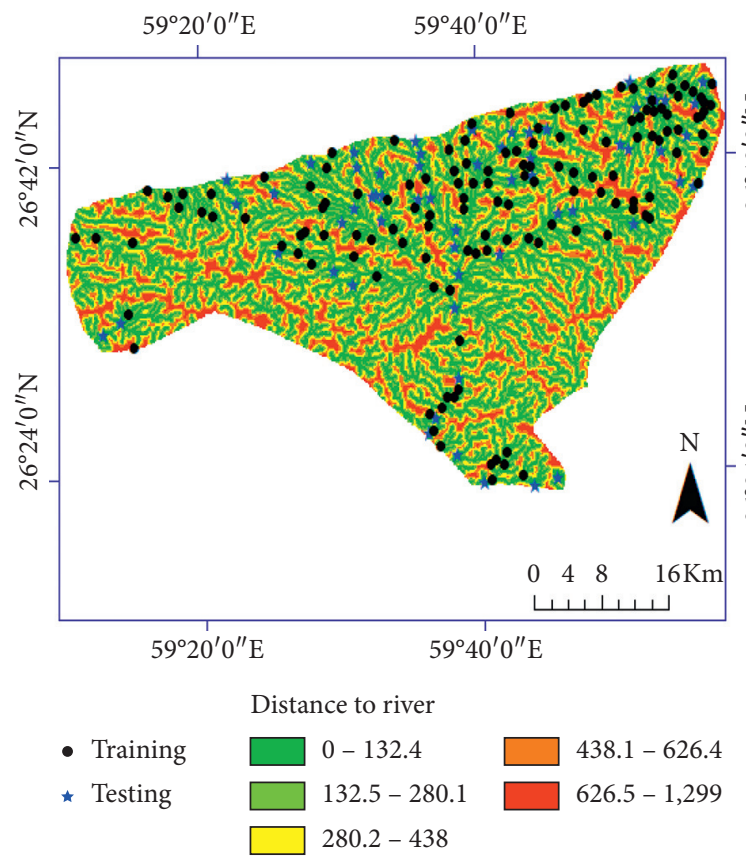

(c)

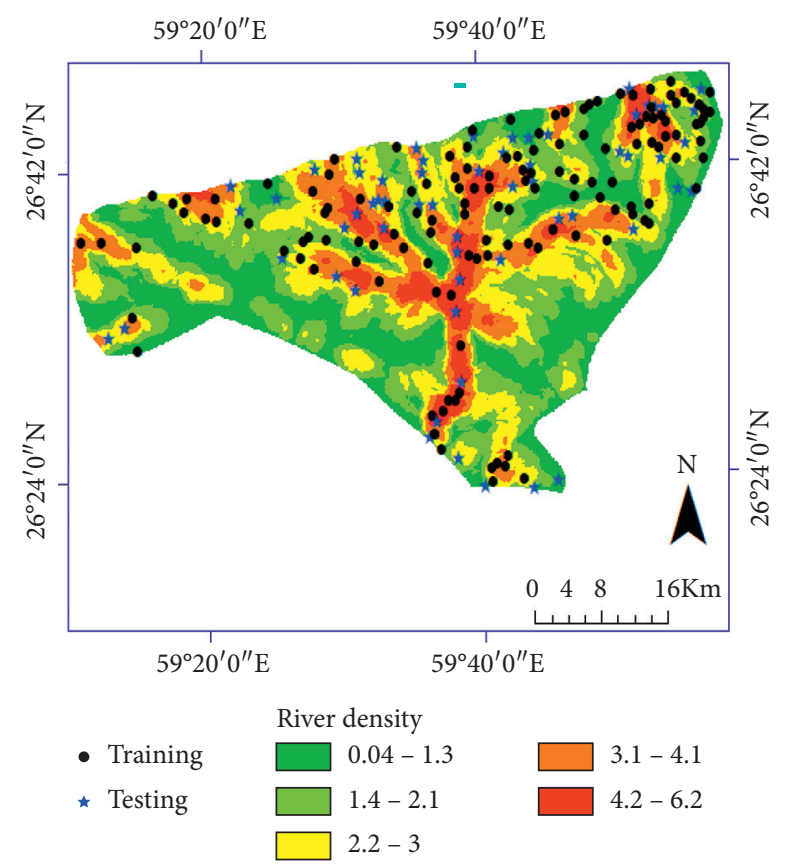

(b)

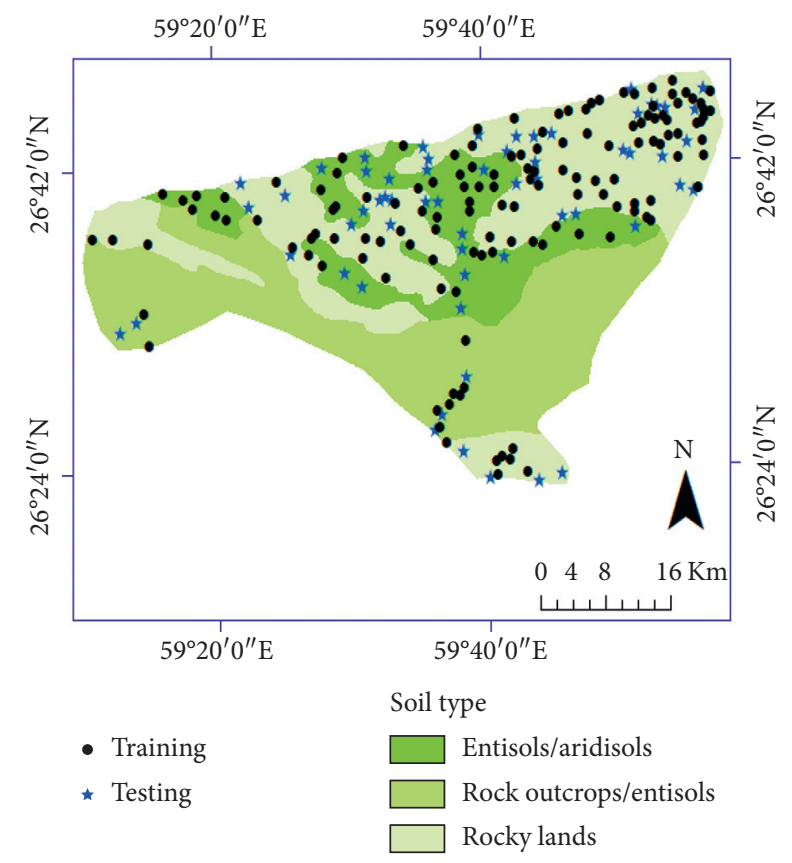

(d)

Figure 6: (a) NDVI. (b) River density. (c) Distance to river. (d) Soil type.

3.5. Time Series Analysis. In this study, twelve pieces of Sentinel-1 data were acquired and used for time series analysis. All data are GRD and IW, from which five imageries are S1B and the remaining are S1A (Table 3). It is worth mentioning that imageries of the dates $31 / 12 / 2019$ and $12 / 01 / 2020$ belong to before and right after the event, respectively.

3.5.1. Data Preprocessing and Processing. reprocessing of twelve images is time-consuming. For efficiency, we employed Graph-Builder to preprocess the data in SNAP environment using the workflow described in Section 3.4.1 (e.g., subset, apply orbit file, thermal noise removal, calibration, speckle filtering, and terrain correction). To extract more information, the imagery should be manipulated on a pixel basis. Texture analysis is an essential method for distinguishing objects, especially in SAR data [34]. This technique was applied to get a better discrimination among different objects. Using pixel info tools in SNAP, flooded areas can be identified initially. Once pixel information of 
TABLE 1: The floods-affecting parameters, source, classes, and scale.

\begin{tabular}{|c|c|c|c|}
\hline Layers & Source & Number of classes & Scale $(\mathrm{m})$ \\
\hline Slope & DEM & $0^{\circ}-5.8^{\circ}, 5.9^{\circ}-13^{\circ}, 14^{\circ}-21^{\circ}, 22^{\circ}-30^{\circ}$, and $31^{\circ}-71^{\circ}$. & $30 * 30$ \\
\hline Elevation & DEM & $522-778,778.1-910,910.1-1080,1081-1313$, and $1314-1936$. & $30 * 30$ \\
\hline Aspect & DEM & $\begin{array}{l}\text { Flat }(-1) \text {, north }(0-22.5 \text { and } 337.5-360) \text {, northeast }(22.5-67.5) \text {, east }(67.5-112.5) \text {, southeast } \\
(112.5-157.5) \text {, south }(157.5-202.5) \text {, southwest }(202.5-247.5) \text {, west }(247.5-292.5) \text {, and northwest } \\
(292.5-337.5) .\end{array}$ & $30 * 30$ \\
\hline Curvature & DEM & Concave, flat, and convex. & $30 * 30$ \\
\hline SPI & DEM & $0-600,600.1-2000,2001-4000,4001-8000$, and $>8000$. & $30 * 30$ \\
\hline TWI & DEM & $2.4-5.8,5.9-7.4,7.5-9.6,9.7-13$, and $14-24$ & $30 * 30$ \\
\hline Lithology & $\begin{array}{c}\text { Geology } \\
\text { map }\end{array}$ & $\begin{array}{l}\text { Crystal tuff, diabase, Eocene flysch, piedmont fan, gabbro, valley terrace deposits, limestone, } \\
\text { pelagic limestone, peridotite, sedimentary mélange, tectonic mélange, tectonized, thinly bedded } \\
\text { sandstone, and undifferentiated limestone. }\end{array}$ & $1: 100.000$ \\
\hline Rainfall & TRMM & $513-562,563-593,594-616$, and $617-669 \mathrm{~mm}$ & $0.2 * 0.25$ \\
\hline NDVI & Sentinel-2 & $-0.28-0.052,0.053-0.083,0.084-0.14,0.15-0.29$, and $0.3-0.87$ & $10 * 10$ \\
\hline River density & DEM & $0.04-1.3,1.4-2.1,2.2-3,3.1-4.1$, and $4.2-6.2 \mathrm{~km} / \mathrm{km}^{2}$. & $30 * 30$ \\
\hline $\begin{array}{l}\text { Distance to } \\
\text { river }\end{array}$ & DEM & $0-132.4,132.5-280.1,280.2-438,438.1-626.4$, and $626.5-1,299 \mathrm{~m}$. & $30 * 30$ \\
\hline Soil type & Soil map & Entisols/aridisols, rock outcrops/entisols, and rocky lands. & $1: 100.000$ \\
\hline
\end{tabular}

TABLE 2: Technical attributes of Sentinel-1 data for flood inventory.

\begin{tabular}{lccc}
\hline Date & Sensor mode and product type & Platform & Path \\
\hline $31 / 12 / 2019$ & IW and GRD & S1B & Ascending \\
$12 / 01 / 2020$ & S & & \\
\hline
\end{tabular}

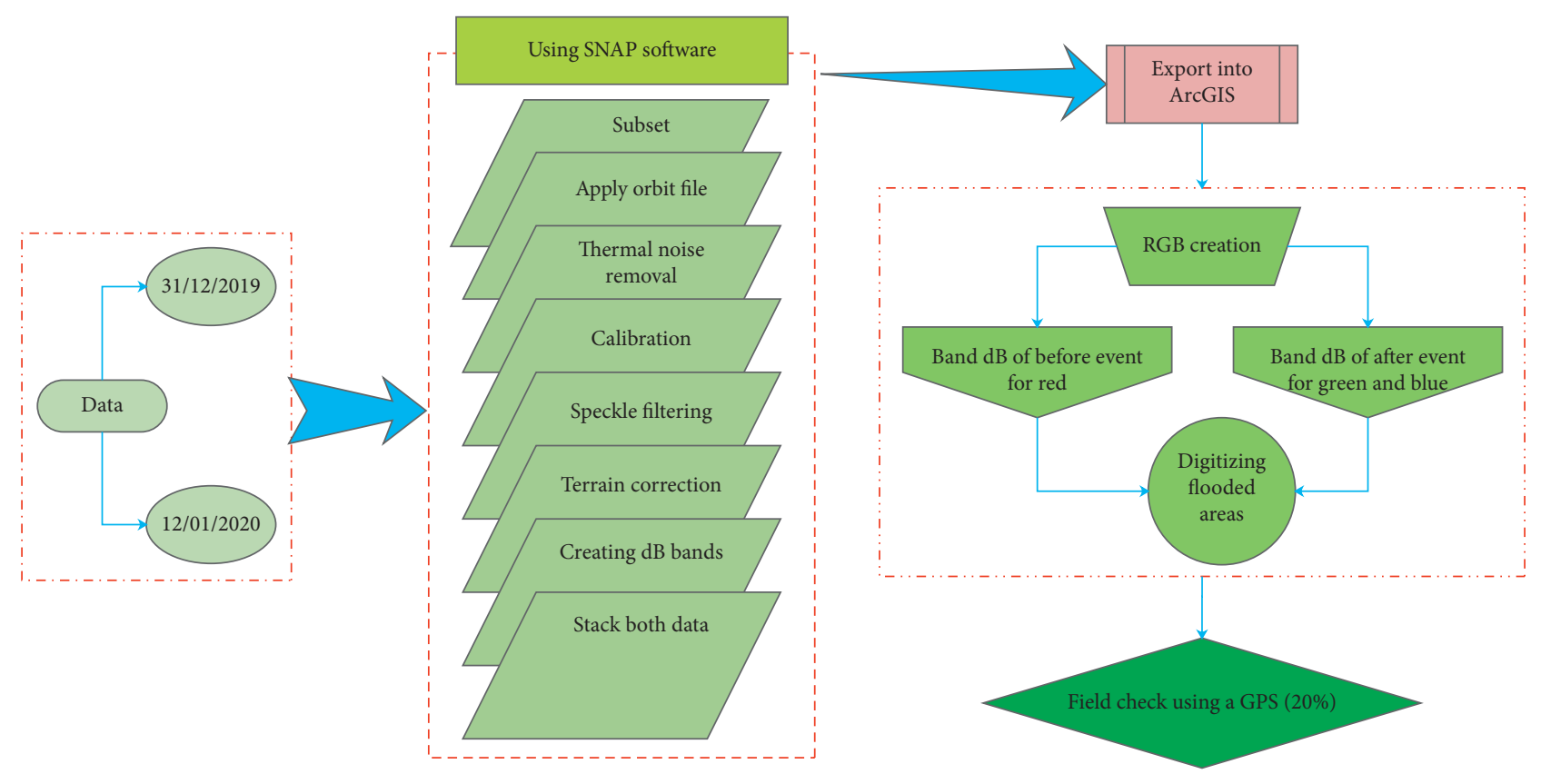

FIgURE 7: Methodology of flood inventory of the study. 
TABLe 3: Technical information of Sentinel-1 data for time series assessment.

\begin{tabular}{lcccc}
\hline No. & Date & Product type & Sensor mode & Platform \\
\hline 1 & $31 / 12 / 2019$ & GRD & IW & S1B \\
2 & $12 / 01 / 2020$ & GRD & IW & S1B \\
3 & $18 / 01 / 2020$ & GRD & IW & S1A \\
4 & $21 / 01 / 2020$ & GRD & IW & S1B \\
5 & $24 / 01 / 2020$ & GRD & IW & S1A \\
6 & $30 / 01 / 2020$ & GRD & IW & S1A \\
7 & $02 / 02 / 2020$ & GRD & IW & S1B \\
8 & $05 / 02 / 2020$ & GRD & IW & S1A \\
9 & $11 / 02 / 2020$ & GRD & IW & S1A \\
10 & $14 / 02 / 2020$ & GRD & IW & S1B \\
11 & $17 / 02 / 2020$ & GRD & IW & S1A \\
12 & $23 / 02 / 2020$ & GRD & IW & \\
\hline
\end{tabular}

flooded areas was recognized, we then extracted it using the band math tools. For further processes, all imageries were exported into ArcGIS as GeoTIFF.

In order to omit single pixels and noise across the data, we postprocessed the data in an ArcGIS environment. First of all, a majority filter has to be applied to the pixels one by one. Before separating the noisy and single pixels from the others by using region group tool, boundaries of pixels should be severed through the boundary clean module. Now the noisy pixels should be selected using set null command. Nibble is a tool by which selected pixels can be eliminated. Moreover, prior to converting into polygon, the data have to be reclassified into two groups of flooded and nonflooded (Figure 8).

\subsection{Background of Susceptibility Models Used}

3.6.1. Alternating Decision Trees (ADTree) Method. The ADT algorithm is a robust technique for modelling [75]. A simple decision stump is required for processing this method $[4,76]$ and the decision tree structure for this model is relatively simple $[75,77]$. Decision and prediction are two types of nodes for ADT model [4], from which prediction node is a conditional statement [75-77]. The model acts like a boosting technique to grow the tree until a specified number is achieved [76]. The final prediction probability is calculated by the weights' summation $[4,75]$. The model can be measured using the following equations:

$$
\begin{aligned}
\alpha & =0.5 * \mathrm{LN} \frac{W+\left(C_{1} \cap C_{2}\right)}{W-\left(C_{1} \cap C_{2}\right)}, \\
B & =0.5 * \mathrm{LN} \frac{W+\left(C_{1} \cap \bar{C}_{2}\right)}{W-\left(C_{1} \cap \bar{C}_{2}\right)}, \\
Z_{t}\left(C_{1} C_{2}\right) & =\sqrt[2]{W+\left(C_{1} \cap C_{2}\right) * W-\left(C_{1} \cap C_{2}\right)} \\
& \sqrt[+]{W+\left(C_{1} \cap C_{2}\left(C_{1} \cap \bar{C}_{2}\right)+W\left(\bar{C}_{2}\right)\right)},
\end{aligned}
$$

where $C_{1}$ is a precondition, $C_{2}$ is a base condition, $\cap$ is intersection, $W$ denotes weights, and $\alpha$ and $b$ are two real numbers (instance to real numbers).

3.6.2. Bagging Ensemble. Finding a best and absolute single technique for susceptibility mapping is very difficult [23]. Recently, hybrid models have been considered as the best solutions for developing new algorithms. For constructing ensemble models and improving the predictive accuracy of single algorithms, bagging is very popular among researchers $[5,71]$. In bagging, training sets are formed by constructing a bootstrap replicate of the original training set $[5,78]$, meaning that, given a training set $(T)$ from $\mathrm{N}$ instance, a new training set is formed by drawing $\mathrm{N}$ classes from $T$ [5]. Each instance has a probability of $1-(1-(1 / N))^{N}$, which will be selected at least once in $\mathrm{N}$ times [78]. Bagging is a method that creates multiple and aggregate classifiers through training classifiers in redistributed training sets [78-80]. Combined training sets produced from bagging classifiers have a lower error rate than the single models $[78,80]$.

3.6.3. Bagging Ensemble-Based Alternating Decision Trees (Bag-ADTree). We used the bagging-based ADTree classifier ensemble (bag-ADTree) that is a hybrid technique of ADTree and bagging ensemble models, as a new algorithm for mapping areas prone to flood in our study area. In bagging methods, there are the number of inputs, including training dataset $D$, inducer $\lceil$, and samples $N$ [78]. Bagging forms an ensemble, which is the combination of the classifiers calculated from the multiple samples [81]. As a whole, we first used the bagging ensemble to create optimal datasets for classification and then applied the ADTree classifier for classifying the classes of floods or nonfloods spatially. Figure 9 shows methodology for bagADTree model. 


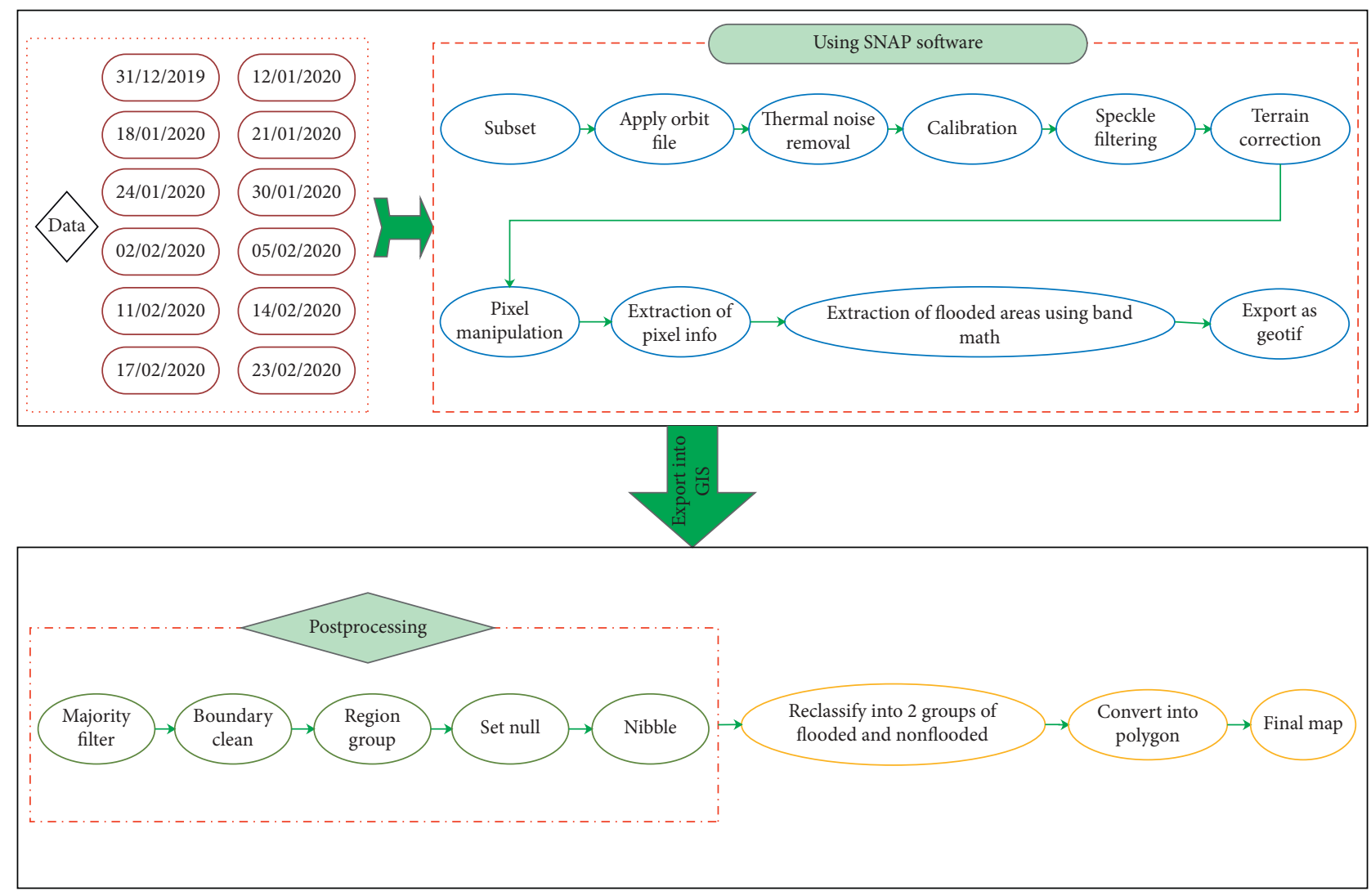

FIgURE 8: Methodology of time series analysis.

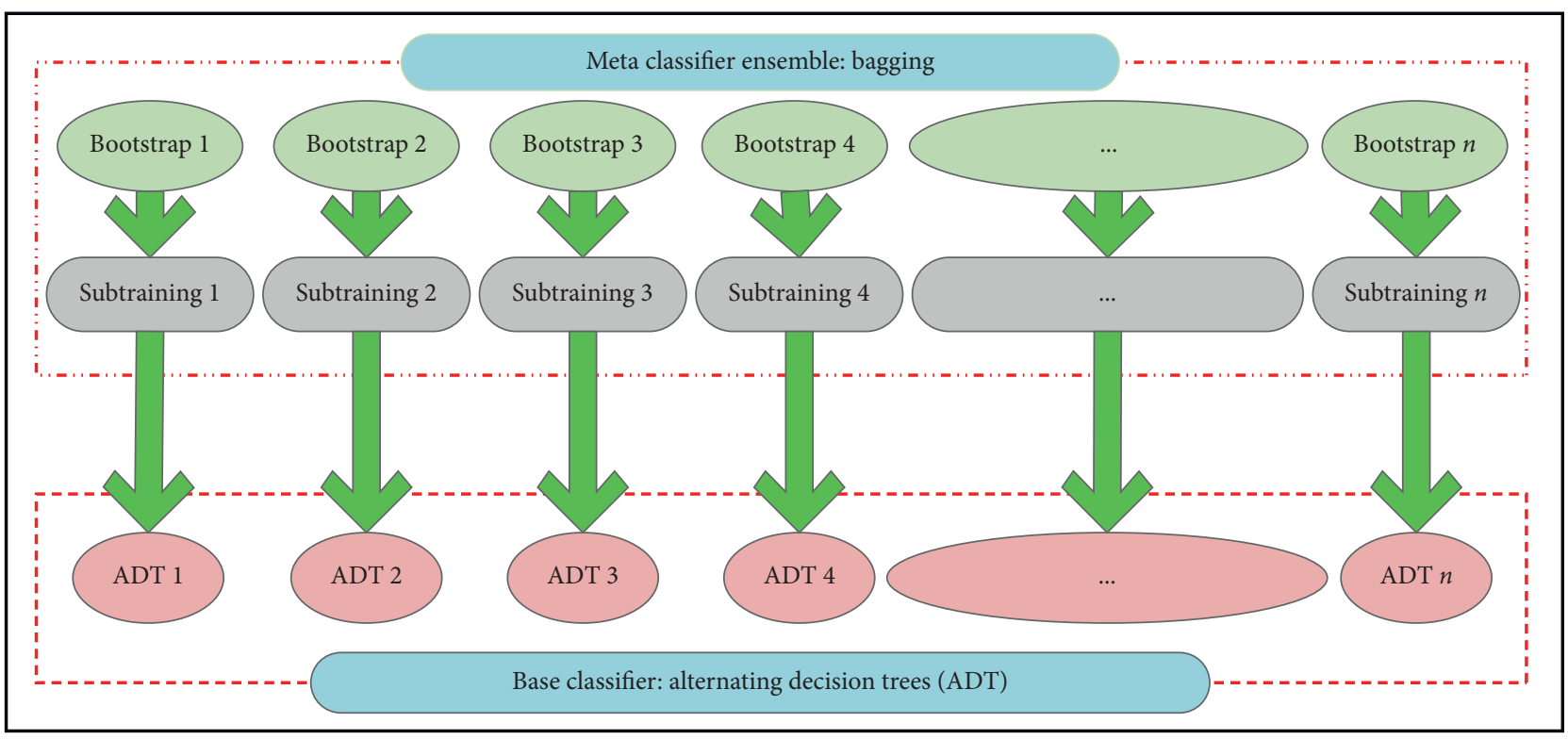

FIGURE 9: Novel technique ensemble framework used in this study. 


\subsection{Evaluation and Comparison}

3.7.1. Root Mean Square Error (RMSE). In order to evaluate the applicability and performances of a new model, proved evaluation methods should be employed, such as RMSE, which can be applied to know about the difference between predicted and observed values $([5,19]$ and Bui et al. $[40,82])$. Researchers tend to use RMSE as a standard way to calculate the errors of models [83]. RMSE can be measured as follows:

$$
\mathrm{RMSE}=\sqrt{\frac{1}{N}} \sum_{i-1}^{N}\left(F_{\text {est. }}-F_{\text {obs. }}\right)^{2},
$$

where estimated floods, real floods, and quantity of floods are $F_{\text {est. }}, F_{\text {obs. }}$, and $N$, respectively.

3.7.2. Overall Accuracy. Overall accuracy needs to be determined for further capability testing of the models. The overall accuracy is normally calculated based on True Negative (TN), True Positive (TP), False Negative (FN), and False Positive (FP) values [5]. TP is the number of flooded pixels that are correctly classified as flood and TN is the number of flooded pixels that are correctly classified as nonflood $[5,18,84]$. FP and $\mathrm{FN}$ are nonflood pixels that are correctly classified as flood and nonflood pixels, respectively $[5,11,63,70]$. Overall accuracy can be measured as follows:

$$
\text { accuracy }=\frac{\mathrm{TP}+\mathrm{TN}}{\mathrm{TP}+\mathrm{TN}+\mathrm{FP}+\mathrm{FN}}
$$

3.7.3. Area under the ROC Curve (AUC). We tested the overall capability of our models via AUC, which is known to be a robust method $([5,10,84]$ and Bui et al. $[40,50])$. Here, specificity (the number of incorrectly classified floods) is located on the $x$-axis, while sensitivity (the number of correctly classified floods) is located on the $y$-axis [85]. A value of 1 indicates that the represented model is perfect and a value of 0 indicates that the model is unideal $[25,86]$. The AUC can be calculated as follows:

$$
\mathrm{AUC}=\frac{\sum \mathrm{TP}+\sum \mathrm{TN}}{M+N}
$$

where $M$ represents the number of total flood pixels and $N$ represents the total nonflood pixels [5].

\section{Results}

4.1. Selection of the Best Factors Using LSA Technique. Using LSA technique in WEKA software, we selected the best factors to model the algorithms. The Latent Variable (LV) values range from 0.06 to 0.64 . Not surprisingly, the highest LV value of 0.64 belongs to rainfall. In order of decreasing importance, the other factors are river density $(\mathrm{LV}=0.35)$, slope $(\mathrm{LV}=0.31)$, distance to river $(\mathrm{LV}=0.29)$,
NDVI $\quad(\mathrm{LV}=0.28)$, lithology $\quad(\mathrm{LV}=0.26)$, elevation $(\mathrm{LV}=0.25)$, aspect $(\mathrm{LV}=0.21)$, curvature $(\mathrm{LV}=0.18)$, TWI $(\mathrm{LV}=0.16)$, soil $(\mathrm{LV}=0.13)$, and SPI $(\mathrm{LV}=0.06)$ (Figure 10).

4.2. Flood Detection Using Sentinel-1 Data. Using SNAP software, a coregistered image was created from a pair of Sentinel-1 data (for before and after the flood event). Before coregistration, we created $\mathrm{dB}$ bands for both data, and using these bands with the RGB window in ArcGIS we identified and digitized the flooded areas. In this model, the flooded areas are differentiated (in red color) from the other areas (preflood water bodies). A total of 199 locations were finally recognized and mapped as flood prone regions (Figure 11).

Because of the local reports for seeing crocodiles in the study area during flooding days (Figure 12), researchers were able to validate $20 \%$ (40 locations) only. These locations were selected randomly and checked within seven working days. It is worth mentioning that the scar of flood appeared in all the validated locations. Figure 13 shows the geographical location of the validated locations.

4.3. Time Series Analysis. From 10 to 12 January 2020 (three days), severe and destructive rainfall occurred in Fanuj County, Iran. The intense rainfall and subsequent minor rainfalls contributed to the gradual residing of flooded areas (Figures 14 and 15) that were among those that experienced a lot of damage, especially economically. This section attempted to study the area of the water using Sentinel-1 time series data. Therefore, twelve images were acquired and analyzed via SNAP 7.0 and ArcGIS 10.5. The results show that, on $23 / 02 / 2020$, the study area returned to the normal situation as before severe flooding (area of water for both dates of before flooding 31/12/2019, and last date, 23/02/ 2020 , was recorded about $5.5 \mathrm{~km}^{2}$ ). Right after rainfall (on $12 / 01 / 2020)$ the area of water was almost $583 \mathrm{~km}^{2}$. Not surprisingly, the amount of water from then showed a remarkable decline date by date. Based on the field survey and the local reports, area of water within the study area was affected by the upper areas' rainfall as well as scattered and local rainfalls during the research period of time; otherwise, the study area could have returned to the normal situation sooner (here on 23/02/2020 the study area could return to the normal situation as before flooding days). More findings indicate that on $02 / 02 / 2020$ the water has lost half of its area (approximately $280 \mathrm{~km}^{2}$ ). The area of water for the other dates is shown in Figures 14 and 15. Before the flooding in December 2019, less than $0.3 \%$ of the area was covered by water. At peak flooding on 12 January 2020 , more than $42 \%$ of the study area was inundated. It took more than a month for flood waters to subside to normal levels.

4.4. Flood Susceptibility Maps (FSM). We generated flood susceptibility maps using ADTree (Figure 16) and bagADTree (Figure 17) methods with four classes of low, 


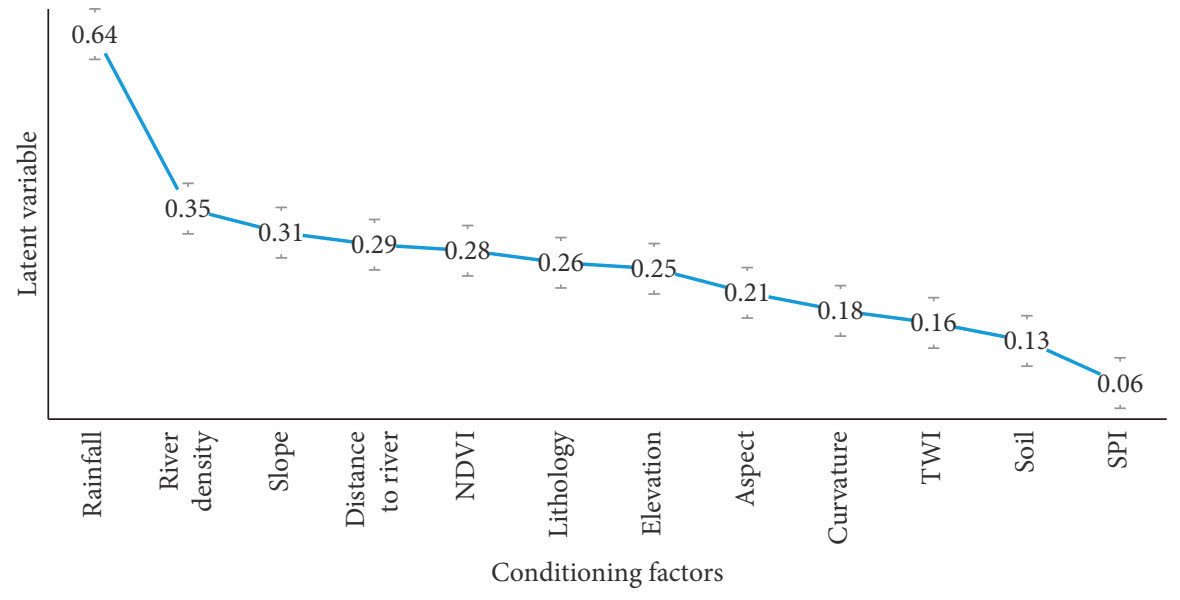

FIgURE 10: Important flood factors selected by LSA technique.

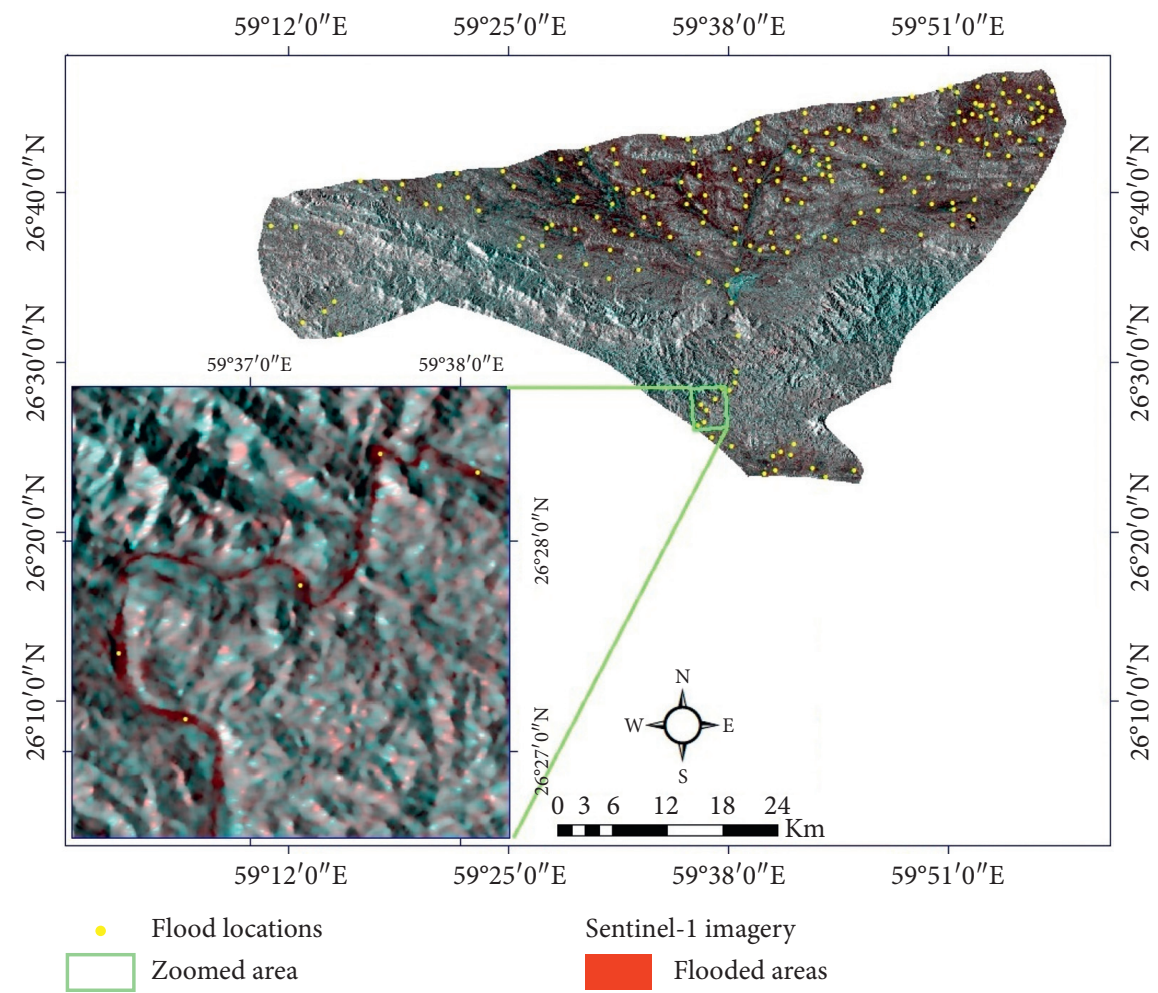

FIgUre 11: Flood detection using Sentinel-1.

moderate, high, and very high using the quantile method in ArcGIS. We extracted the area percentages of each class for the two maps using ArcGIS. It appears that, for the ADTree model, the moderate class has the largest area percentage of
$29 \%\left(528.5 \mathrm{~km}^{2}\right)$, followed by high, $28 \%\left(518.86 \mathrm{~km}^{2}\right)$, very high, $24 \%\left(432.68 \mathrm{~km}^{2}\right)$, and low, $19 \%\left(354.8 \mathrm{~km}^{2}\right)$, classes. For the bag-ADTree model, the area percentage is $16 \%$ $\left(293.89 \mathrm{~km}^{2}\right), 28 \%\left(509.7 \mathrm{~km}^{2}\right), 31 \%\left(563.7 \mathrm{~km}^{2}\right)$, and $25 \%$ 


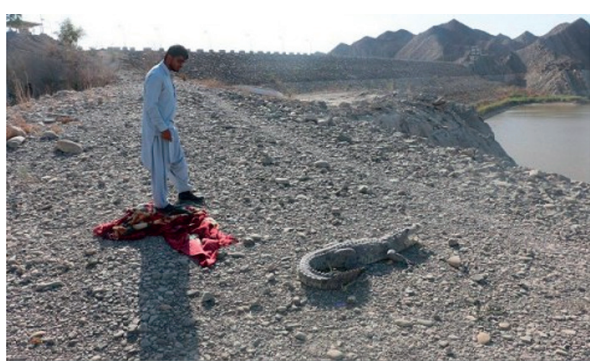

(a)

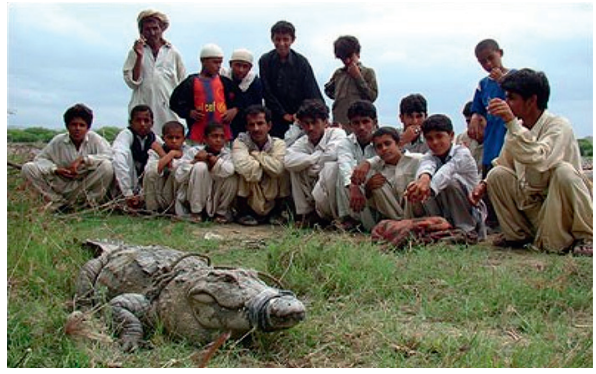

(c)

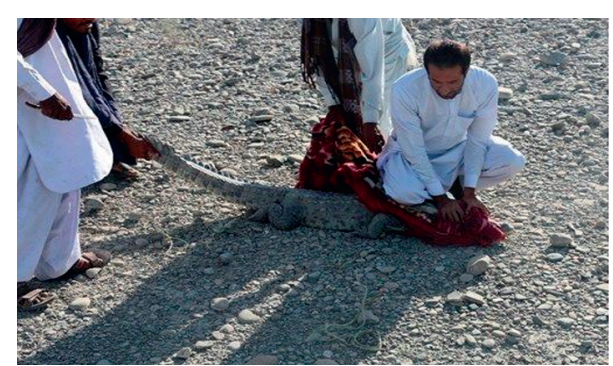

(b)

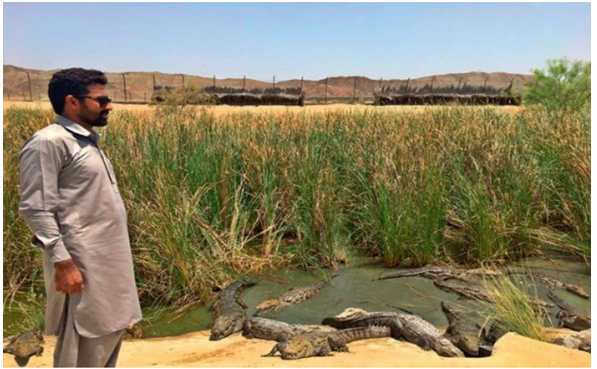

(d)

FIGURE 12: Crocodiles during flooding in the study area [87].

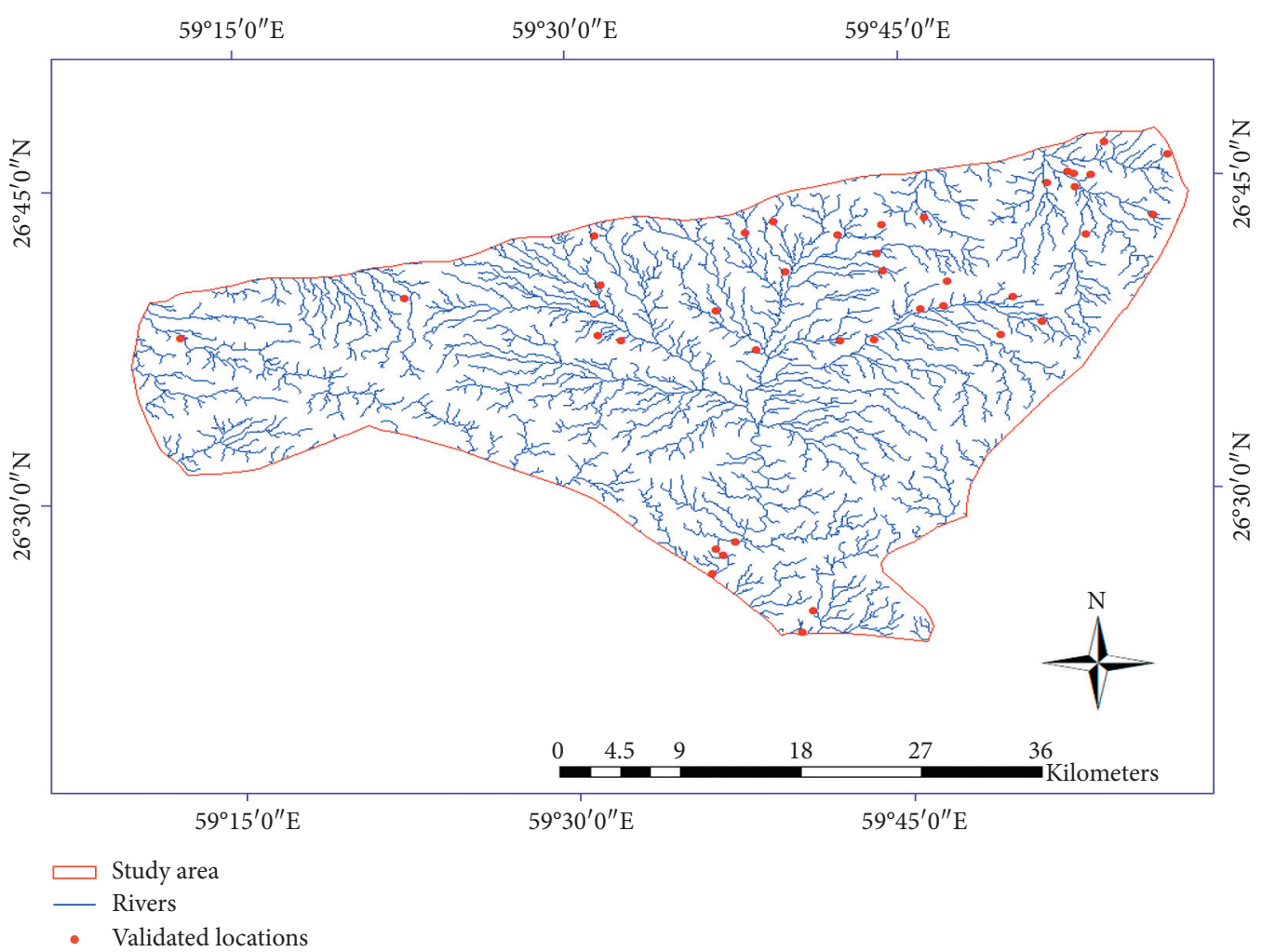

FIgURE 13: Validated locations in the study area using GPS. 


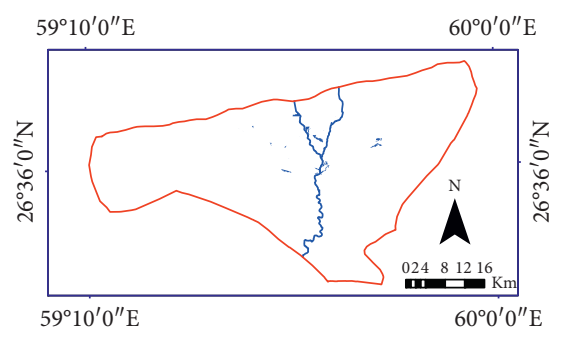

3 Study area

3 Flooded areas

(a)

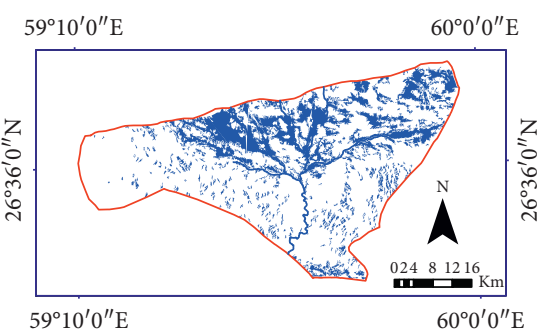

3 Study area

3 Flooded areas

(d)

$59^{\circ} 10^{\prime} 0^{\prime \prime} \mathrm{E} \quad 60^{\circ} 0^{\prime} 0^{\prime \prime} \mathrm{E}$

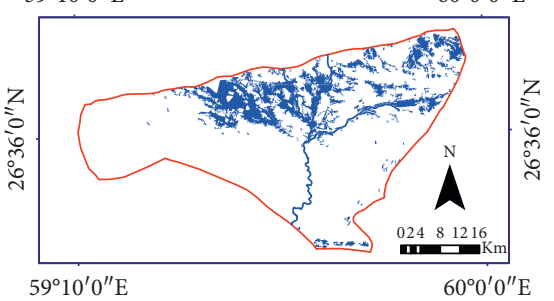

$\checkmark 3$ study area

3 Flooded areas

(g)

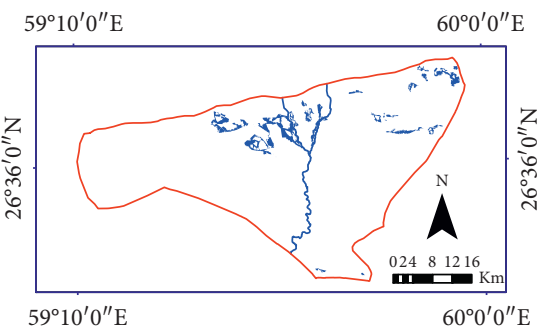

$\checkmark$ study area

Flooded areas

(j)

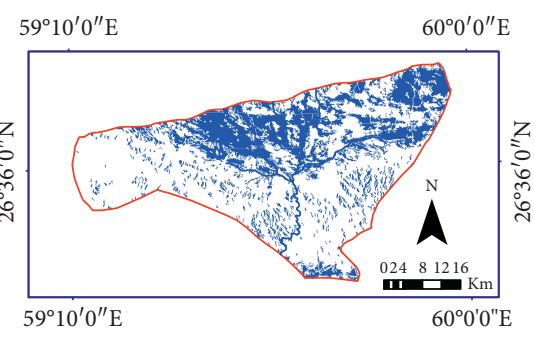

3 Study area

Flooded areas

(b)

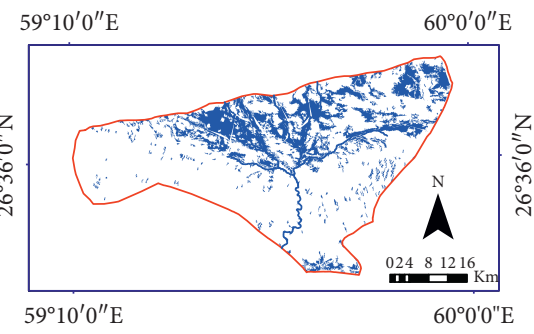

$\checkmark 3$ study area

3 Flooded areas

(e)

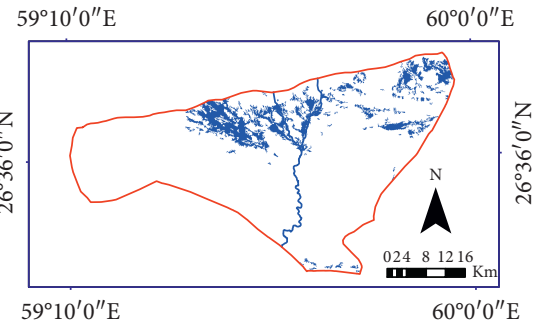

$\checkmark$ Study area

(h)

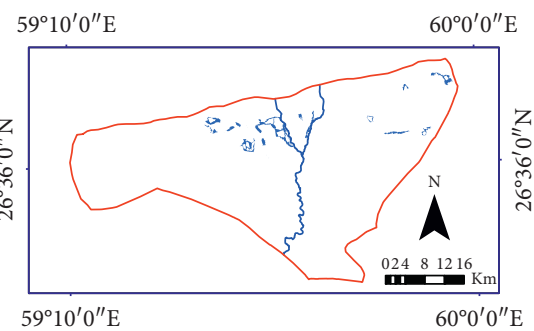

$\checkmark$ Study area

(k)

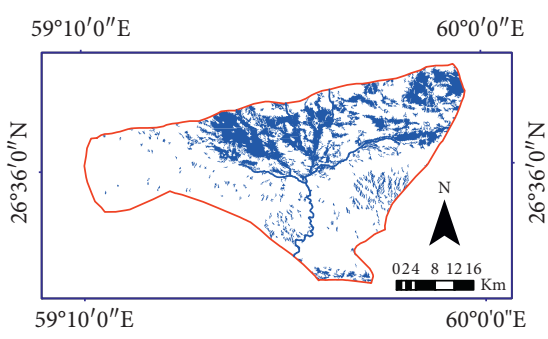

$\checkmark$ Study area

$\checkmark$ Flooded areas

(c)

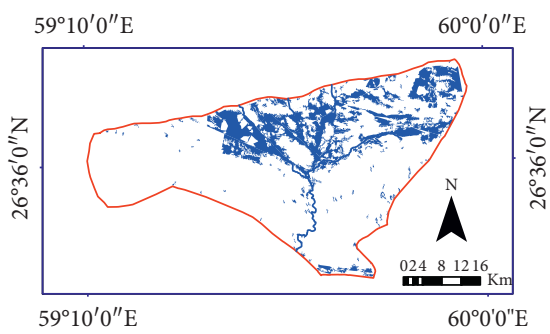

3 study area

Flooded areas

(f)

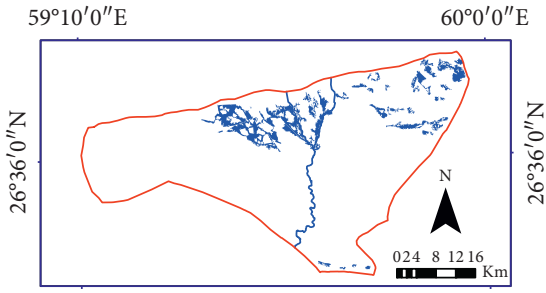

$59^{\circ} 10^{\prime} 0^{\prime \prime} \mathrm{E}$

$60^{\circ} 0^{\prime} 0^{\prime \prime} \mathrm{E}$

$\checkmark$ Study area

3 Flooded areas

(i)

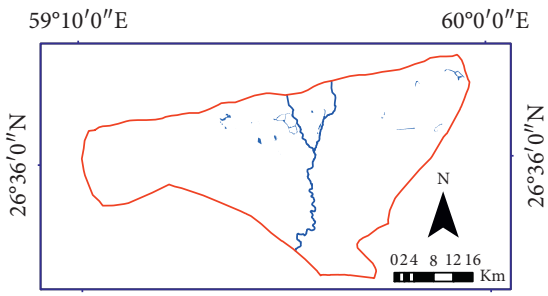

$59^{\circ} 10^{\prime} 0^{\prime \prime} \mathrm{E}$ $60^{\circ} 0^{\prime} 0^{\prime \prime} \mathrm{E}$

3 study area

Flooded areas

(1)

Figure 14: Flooded areas determined by Sentinel-1 data for different times. (a) 31 December 2019. (b) 12 January 2020 . (c) 18 January 2020. (d) 21 January 2020. (e) 24 January 2020. (f) 30 January 2020. (g) 2 February 2020. (h) 5 February 2020. (i) 11 February 2020. (j) 14 February 2020. (k) 17 February 2020. (l) 23 February 2020. 


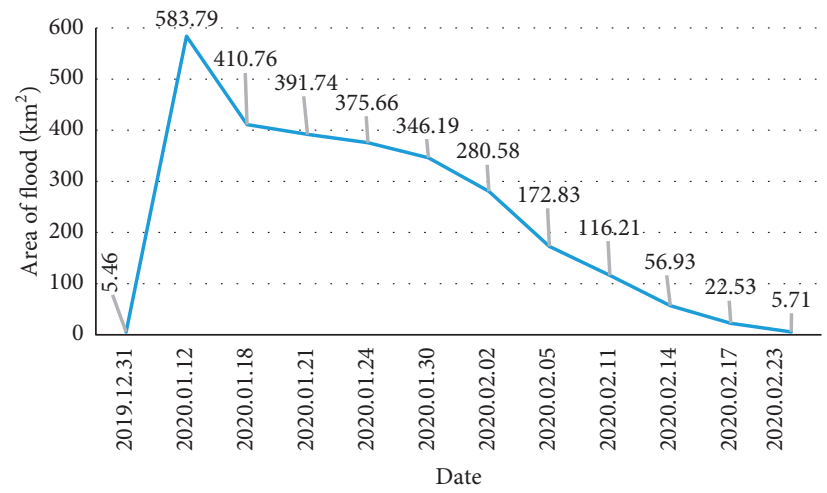

FIgURe 15: Diminishing cumulative area of flooding over twelve time periods.

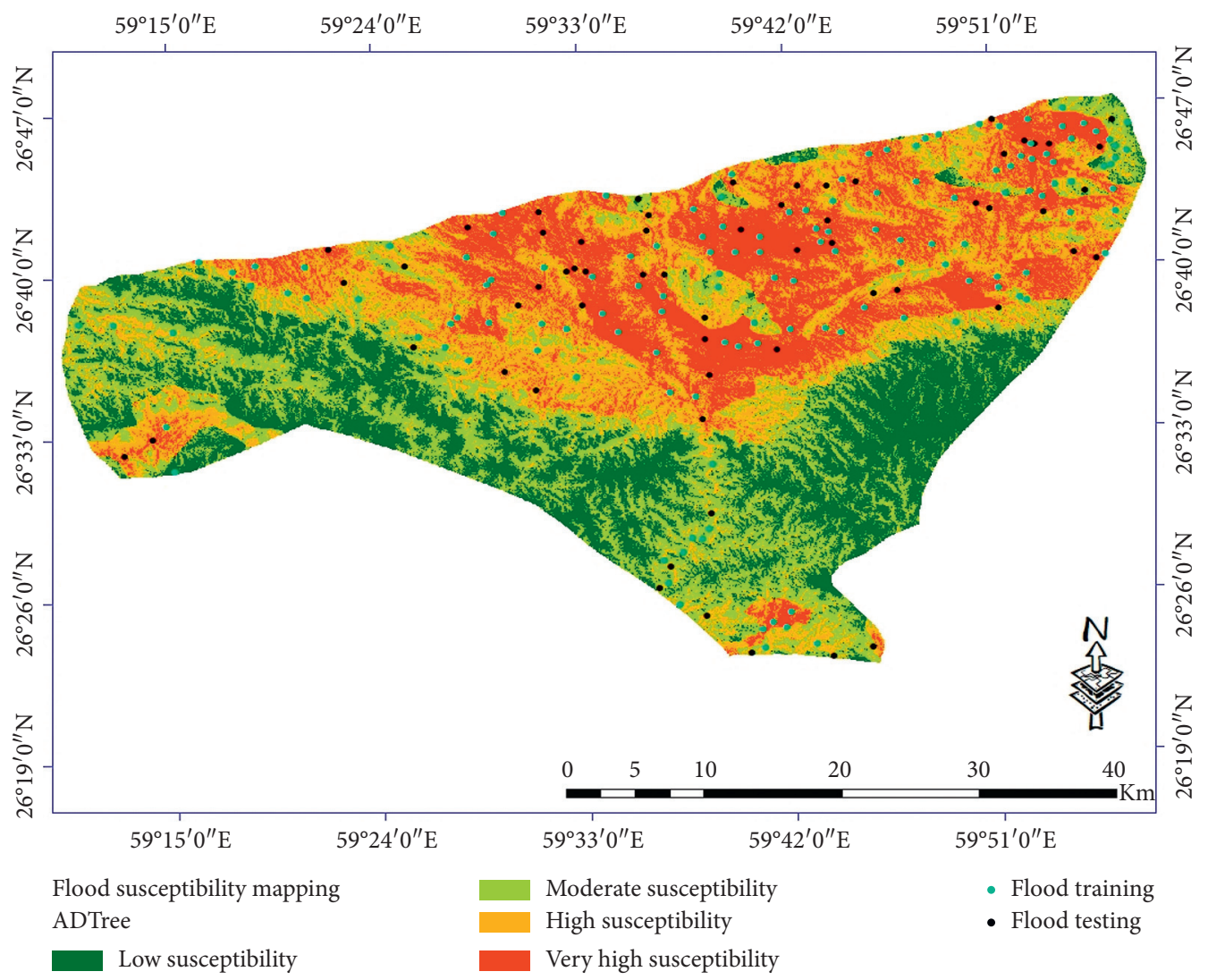

FIgURE 16: Flood susceptibility map derived from ADTree model.

$\left(467.6 \mathrm{~km}^{2}\right)$ for the low, moderate, high, and very high classes, respectively.

4.5. Evaluation and Comparison. Validations were applied to determine the accuracy and prediction capabilities of the models. The ROC was applied for the two FSMs using the training and validation datasets, which is shown in
Figure 18 and Table 4. Both models displayed reasonable results with respective success rates of 0.736 and 0.714 and prediction rates of 0.786 and 0.784 for the bag-ADTree and the ADTree models, respectively. The results demonstrate that the bag-ADTree model was marginally better than ADTree algorithm. The bag-ADTree model also performed slightly better in terms of accuracy and RMSE (Table 4). 


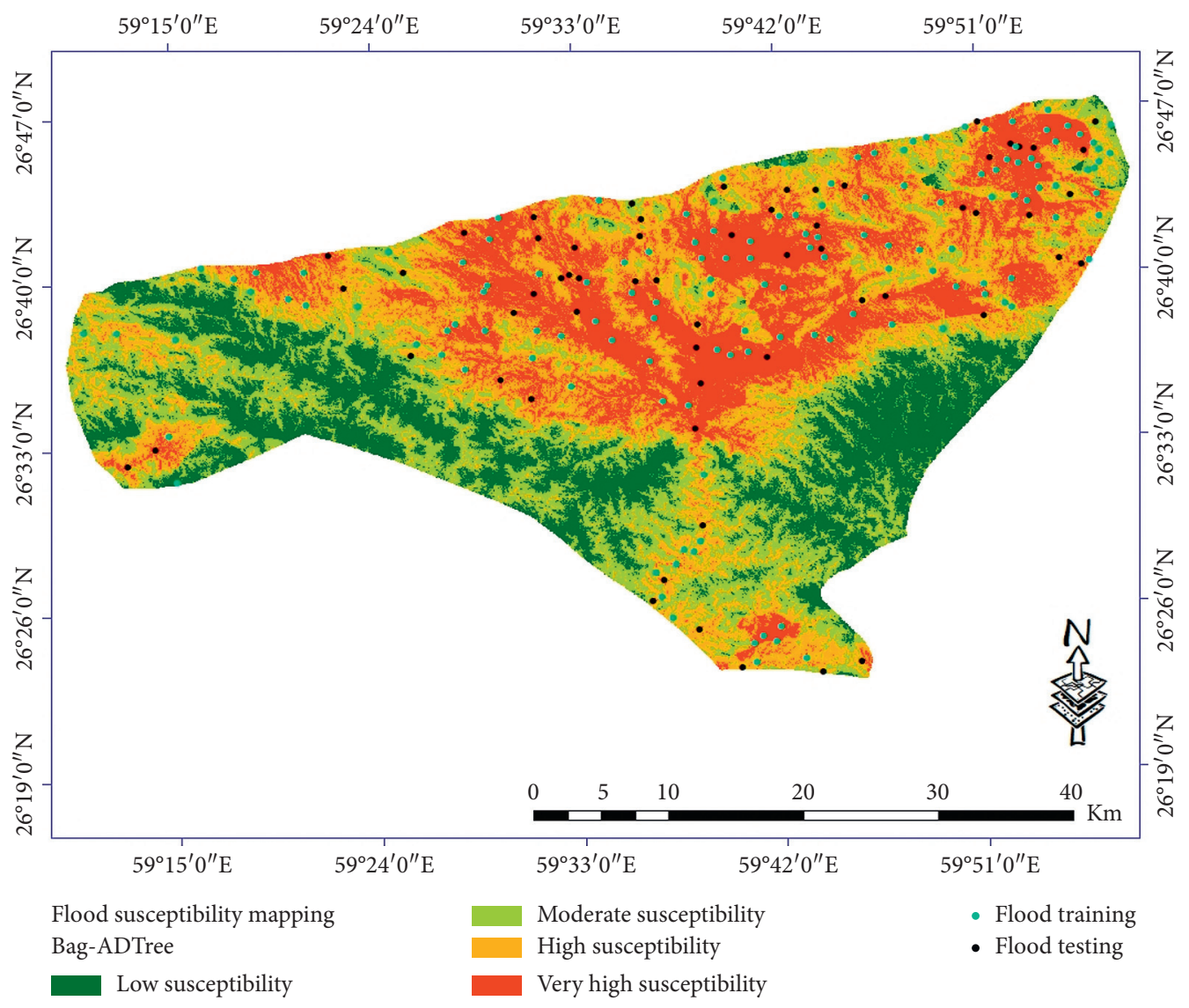

FIGURE 17: Flood susceptibility map derived from bag-ADTree technique.

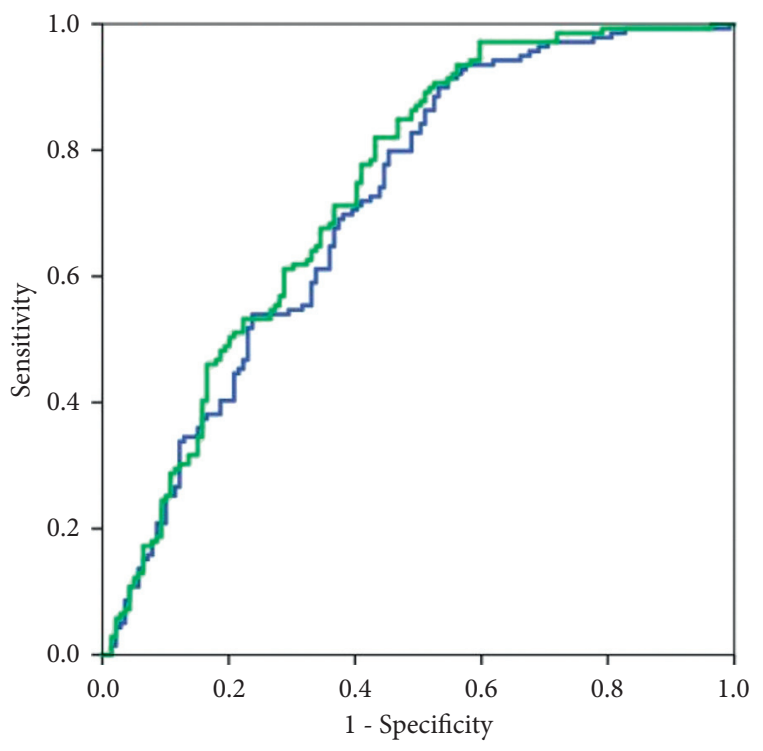

- ADTree $(\mathrm{AUC}=0.714)$

— Bag-ADTree $(\mathrm{AUC}=0.736)$

(a)

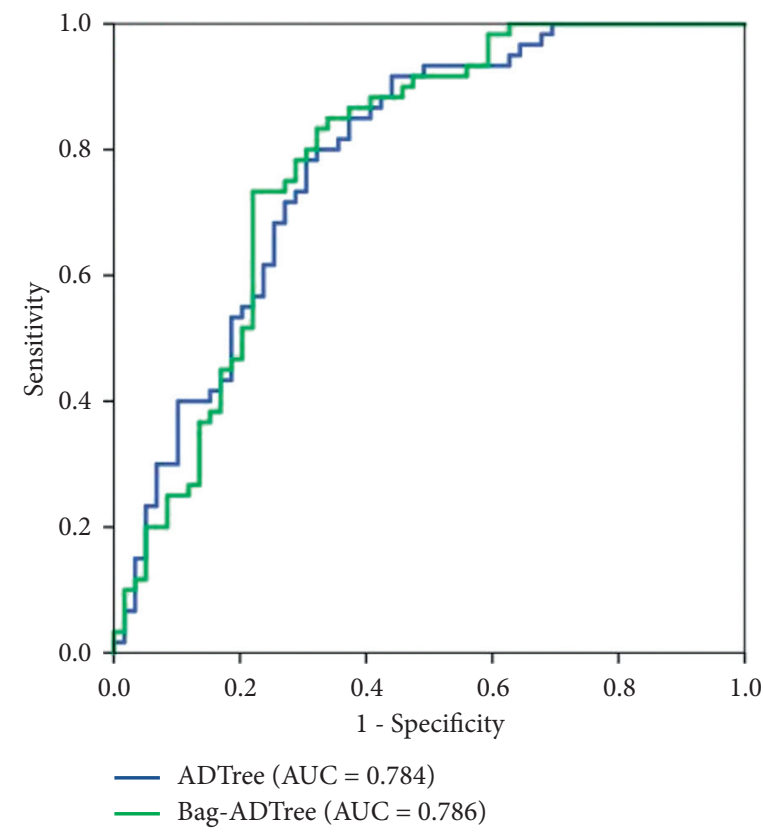

(b)

Figure 18: The success and prediction rate curves for flooding map. (a) Success rate and (b) prediction rate. 
TABLE 4: Evaluation of the performance of ADTree and bagADTree models.

\begin{tabular}{lccc}
\hline & Models & ADTree & Bag-ADTree \\
\hline Parameters & & & \\
Accuracy (\%) & & 85.44 & 86.61 \\
RMSE & & 0.31 & 0.30 \\
AUC & Success rate & 0.714 & 0.736 \\
& Prediction rate & 0.784 & 0.786 \\
\hline
\end{tabular}

\section{Discussion and Conclusion}

Complex natural hazards, such as flash floods, can never be entirely eliminated from society. Flood prediction methods can help mitigate the loss of human life and economic damage. Widespread flooding over the last three years in Iran motivated us to improve flood susceptibility mapping capabilities. We chose Sentinel-1 data because it was freely available and applicable for studying flood hazard [84]. In recent years, ensemble techniques have become mainstream in flood and landslide susceptibility assessment and were favoured over single-evaluation methods due to their higher predictive capabilities $[1,10]$. We previously used the bagADTree model successfully for landslide susceptibility [88] and tested it for flood susceptibility mapping in this study.

The factors for generating flood susceptibility mapping are complex, so that their mechanisms remain under study [1]. From initial fifteen flood susceptibility factors, we excluded topographic position index (TPI), sediment transport index (STI), and terrain ruggedness index (TRI) as they had a negligible effect on flood occurrence based on LSA analysis. The analysis used included twelve factors. They are rainfall, river, NDVI, lithology, elevation, aspect, curvature, TWI, soil, and SPI. The most important factor was rainfall for flood detection.

We used SNAP and ArcGIS together to preprocess, process, and postprocess a pair of Sentinel-1 data to extract areas prone to flood in the study area, where a total of 199 locations were finally identified and mapped, from which $20 \%$ (40 locations) were randomly selected to be validated in the study area. Validation of the selected locations was done through a handheld GPS and proved that the locations were extracted correctly. Because of the local scattered rainfall and upper cities' rainfall pouring into the study area, about fifty days were needed until the study area could clear from surface water and return back to the normal situation. The results of the time series analysis showed that the high and very high susceptible classes overlap with the flood prone areas.

We selected ADTree and bag-ADTree algorithms to map areas susceptible to flooding; however, ADTree model has been widely used for hazard studies but, in the current study, it was boosted using bagging model. In the models, the low susceptible area had the smallest areas of $355 \mathrm{~km}^{2}$ and $294 \mathrm{~km}^{2}$, respectively. For the ADTree model, the moderate susceptible area with $529 \mathrm{~km}^{2}$ is the biggest area, while the biggest area for bag-ADTree algorithm belongs to the high susceptible area with $564 \mathrm{~km}^{2}$. Despite these differences, based on the evaluation performance using a few statistical measurements, including RMSE, accuracy, and ROC curve, the models can map areas with high accuracy. RMSE for ADTree and bag-ADTree algorithms was 0.31 and 0.3 , respectively. With $86.61 \%$ accuracy compared with $85.44 \%$ for ADTree, bag-ADTree model showed itself as a marginally superior technique to map areas prone to flooding. Success rates were also higher for the bag-ADTree model (0.736) compared to the ADTree model $(0.714)[1,10]$. Prediction rates were almost identical, but the bag-ADTree model came in marginally better with a ratio of 0.786 , compared to 0.784 for the ADTree model. Overall, according to the obtained results, the authors declare that our objectives have been achieved in the current study.

One of the limitations of this study comes from the time series input data, which provides no information related to flooding depth but just the area of water. Another source of error is associated with the RADAR remote sensing that is sensitive to soil moisture such that nonflooded wet soils could be mistaken for flooded units. We hope that the findings of this study may help guide local policy and decision-makers to better cope with future floods. We recommended the use of our bag-ADTree model for future flood susceptibility modelling and that infiltration and permeability of area soils and rock be given more studies.

\section{Data Availability}

The applied data for current research is under copyright rule of University of Tabriz in Iran. The data used in this manuscript were collected from scihub.copernicus.eu website and preprocessed, processed, and postprocessed using SNAP software and ArcGIS software, which are available from the corresponding author upon request.

\section{Conflicts of Interest}

The authors declare no conflicts of interest.

\section{Acknowledgments}

This work was financially supported by University of Tabriz, Iran (no. 102/1670), and Lulea University of Technology, Lulea, Sweden.

\section{References}

[1] W. Chen, H. Hong, S. Li et al., "Flood susceptibility modelling using novel hybrid approach of reduced-error pruning trees with bagging and random subspace ensembles," Journal of Hydrology, vol. 575, pp. 864-873, 2019.

[2] B. Choubin, E. Moradi, M. Golshan, J. Adamowski, F. SajediHosseini, and A. Mosavi, "An ensemble prediction of flood susceptibility using multivariate discriminant analysis, classification and regression trees, and support vector machines," Science of the Total Environment, vol. 651, pp. 2087-2096, 2019.

[3] S. Birkholz, M. Muro, P. Jeffrey, and H. M. Smith, "Rethinking the relationship between flood risk perception and flood management," Science of the Total Environment, vol. 478, pp. 12-20, 2014. 
[4] K. Khosravi, B. T. Pham, K. Chapi et al., "A comparative assessment of decision trees algorithms for flash flood susceptibility modeling at Haraz watershed, northern Iran," Science of the Total Environment, vol. 627, pp. 744-755, 2018.

[5] H. Shahabi, A. Shirzadi, K. Ghaderi et al., "detection and susceptibility mapping using sentinel-1 remote sensing data and a machine learning approach: hybrid intelligence of bagging ensemble based on K-nearest neighbor classifier," Remote Sensing, vol. 12, no. 2, p. 266.

[6] Wikipedia, Category: Floods in Iran, Wikipedia, San Francisco, CA, USA, 2020a, https://en.wikipedia.org/wiki/Category:Floods_ in_Iran.

[7] R. Costache, "Flash-Flood Potential assessment in the upper and middle sector of Prahova river catchment (Romania). A comparative approach between four hybrid models," Science of The Total Environment, vol. 659, pp. 1115-1134, 2019.

[8] O. Rahmati, H. R. Pourghasemi, and H. Zeinivand, "Flood susceptibility mapping using frequency ratio and weights-ofevidence models in the Golastan Province, Iran," Geocarto International, vol. 31, no. 1, pp. 42-70, 2016 a.

[9] S. V. R. Termeh, A. Kornejady, H. R. Pourghasemi, and S. Keesstra, "Flood susceptibility mapping using novel ensembles of adaptive neuro fuzzy inference system and metaheuristic algorithms," Science of the Total Environment, vol. 615 , pp. 438-451, 2018 b.

[10] K. Chapi, V. P. Singh, A. Shirzadi et al., "A novel hybrid artificial intelligence approach for flood susceptibility assessment," Environmental Modelling \& Software, vol. 95, pp. 229-245, 2017.

[11] B. Pradhan, "Flood susceptible mapping and risk area delineation using logistic regression, GIS and remote sensing," Journal of Spatial Hydrology, vol. 9, no. 2, 2010.

[12] D. Tien Bui, K. Khosravi, S. Li et al., "New hybrids of anfis with several optimization algorithms for flood susceptibility modeling," Water, vol. 10, no. 9, p. 1210, 2018.

[13] L. Alfieri, B. Bisselink, F. Dottori et al., "Global projections of river flood risk in a warmer world," Earth's Future, vol. 5, no. 2, pp. 171-182, 2017.

[14] Wikipedia, Flood, Wikipedia, San Francisco, CA, USA, 2020c, https://en.wikipedia.org/wiki/Flood.

[15] ISNA, 2,400 Major Floods in Iran in 50 Years, ISNA, Tehran, Iran, 2020, https://www.isna.ir/news/98043116619/.

[16] S. Lee, J.-C. Kim, H.-S. Jung, M. J. Lee, and S. Lee, "Spatial prediction of flood susceptibility using random-forest and boosted-tree models in Seoul metropolitan city, Korea," Geomatics, Natural Hazards and Risk, vol. 8, no. 2, pp. 1185-1203, 2017.

[17] F. Chen, J. You, P. Tang, W. Zhou, N. Masini, and R. Lasaponara, "Unique performance of spaceborne SAR remote sensing in cultural heritage applications: overviews and perspectives," Archaeological Prospection, vol. 25, no. 1, pp. 71-79, 2018.

[18] A. Mohammadi, B. A. Baharin, and H. Shahabi, "Land cover mapping using a novel combination model of satellite imageries: case study of a part of the Cameron highlands, Pahang, Malaysia," Applied Ecology and Environmental Research, vol. 17, no. 2, pp. 1835-1848, 2019.

[19] S. Samanta, C. Koloa, D. Kumar Pal, and B. Palsamanta, "Flood risk analysis in lower part of Markham river based on multi-criteria decision approach (MCDA)," Hydrology, vol. 3, no. 3, p. 29, 2016.

[20] S. Lee, S. Lee, M.-J. Lee, and H.-S. Jung, "Spatial assessment of urban flood susceptibility using data mining and geographic information System (GIS) tools," Sustainability, vol. 10, no. 3 , p. $648,2018$.

[21] S. Samanta, D. K. Pal, and B. Palsamanta, "Flood susceptibility analysis through remote sensing, GIS and frequency ratio model," Applied Water Science, vol. 8, no. 2, p. 66, 2018.

[22] S. Janizadeh, M. Avand, A. Jaafari et al., "Prediction success of machine learning methods for flash flood susceptibility mapping in the tafresh watershed, Iran," Sustainability, vol. 11, no. 19, p. 5426, 2019.

[23] H. Shafizadeh-Moghadam, R. Valavi, H. Shahabi, K. Chapi, and A. Shirzadi, "Novel forecasting approaches using combination of machine learning and statistical models for flood susceptibility mapping," Journal of Environmental Management, vol. 217, pp. 1-11, 2018.

[24] M. S. Tehrany, B. Pradhan, and M. N. Jebur, "Flood susceptibility mapping using a novel ensemble weights-of-evidence and support vector machine models in GIS," Journal of Hydrology, vol. 512, pp. 332-343, 2014.

[25] K. Khosravi, A. M. Melesse, H. Shahabi, A. Shirzadi, K. Chapi, and H. Hong, "Flood susceptibility mapping at ningdu catchment, China using bivariate and data mining techniques," Extreme Hydrology and Climate Variability, pp. 419-434, Elsevier, Amsterdam, The Netherlands, 2019.

[26] M.-J. Chapi and J.-E. Kang, "Predictive flooded area susceptibility and verification using GIS and frequency ratio," Journal of the Korean Association of Geographic Information Studies, vol. 15, no. 2, pp. 86-102, 2012.

[27] M.-J. Lee, J.-e. Kang, and S. Jeon, “Application of frequency ratio model and validation for predictive flooded area susceptibility mapping using GIS," in Proceedings of the 2012 IEEE International Geoscience and Remote Sensing Symposium, pp. 895-898, IEEE, Munich, Germany, July 2012.

[28] M. S. Tehrany and L. Kumar, "The application of a Dempster-Shafer-based evidential belief function in flood susceptibility mapping and comparison with frequency ratio and logistic regression methods," Environmental Earth Sciences, vol. 77, no. 13, p. 490, 2018.

[29] U. Dano, A.-L. Balogun, A.-N. Matori et al., "Flood susceptibility mapping using GIS-based analytic network process: a case study of Perlis, Malaysia," Water, vol. 11, no. 3, p. 615, 2019.

[30] M. M. de Brito, M. Evers, and A. D. S. Almoradie, "Participatory flood vulnerability assessment: a multi-criteria approach," Hydrology \& Earth System Sciences, vol. 22, no. 1, 2018.

[31] W. Zhang, X. Zhang, X. Fu, and Y. Liu, "A grey analytic network process (ANP) model to identify storm tide risk," in Proceedings of the 2009 IEEE International Conference on Grey Systems and Intelligent Services (GSIS 2009), pp. 582-587, IEEE, Nanjing, China, November 2009.

[32] A. E. Al-Juaidi, A. M. Nassar, and O. E. Al-Juaidi, "Evaluation of flood susceptibility mapping using logistic regression and GIS conditioning factors," Arabian Journal of Geosciences, vol. 11, no. 24, p. 765, 2018.

[33] S.-Y. Liong and C. Sivapragasam, "Flood stage forecasting with support vector machines," Journal of the American Water Resources Association, vol. 38, no. 1, pp. 173-186, 2002.

[34] M. S. Tehrany, B. Pradhan, S. Mansor, and N. Ahmad, "Flood susceptibility assessment using GIS-based support vector machine model with different kernel types," Catena, vol. 125, pp. 91-101, 2015.

[35] W. Chen, Y. Li, W. Xue et al., "Modeling flood susceptibility using data-driven approaches of naïve Bayes tree, alternating 
decision tree, and random forest methods," Science of The Total Environment, vol. 701, p. 134979, 2020.

[36] M. Ahmadlou, M. Karimi, S. Alizadeh et al., "Flood susceptibility assessment using integration of adaptive networkbased fuzzy inference system (ANFIS) and biogeographybased optimization (BBO) and BAT algorithms (BA)," Geocarto International, vol. 34, no. 11, pp. 1252-1272, 2019.

[37] H. Hong, M. Panahi, A. Shirzadi et al., "Flood susceptibility assessment in Hengfeng area coupling adaptive neuro-fuzzy inference system with genetic algorithm and differential evolution," Science of The Total Environment, vol. 621, pp. 1124-1141, 2018.

[38] C. Habibi and T. Ouarda, "Regional flood frequency analysis at ungauged sites using the adaptive neuro-fuzzy inference system," Journal of Hydrology, vol. 349, no. 1-2, pp. 31-43, 2008.

[39] Y. Wang, H. Hong, W. Chen et al., "Flood susceptibility mapping in Dingnan County (China) using adaptive neurofuzzy inference system with biogeography based optimization and imperialistic competitive algorithm," Journal of Environmental Management, vol. 247, pp. 712-729, 2019 b.

[40] D. T. Bui, M. Panahi, H. Shahabi et al., "Novel hybrid evolutionary algorithms for spatial prediction of floods," Scientific Reports, vol. 8, no. 1, pp. 1-14, 2018.

[41] H. Hong, J. Liu, and A.-X. Zhu, "Modeling landslide susceptibility using LogitBoost alternating decision trees and forest by penalizing attributes with the bagging ensemble," Science of the Total Environment, vol. 718, p. 137231, 2020.

[42] Y. Wu, Y. Ke, Z. Chen, S. Liang, H. Zhao, and H. Hong, "Application of alternating decision tree with AdaBoost and bagging ensembles for landslide susceptibility mapping," Catena, vol. 187, p. 104396, 2020.

[43] W. Ahmad, B. Pradhan, S. Li et al., "Novel hybrid integration approach of bagging-based Fisher's linear discriminant function for groundwater potential analysis," Natural Resources Research, vol. 28, no. 4, pp. 1239-1258, 2019.

[44] E. Ahmadisharaf, M. Tajrishy, and N. Alamdari, "Integrating flood hazard into site selection of detention basins using spatial multi-criteria decision-making," Journal of Environmental Planning and Management, vol. 59, no. 8, pp. 13971417, 2016.

[45] M. M. de Brito and M. Evers, "Multi-criteria decision-making for flood risk management: a survey of the current state of the art," Natural Hazards and Earth System Sciences, vol. 16, no. 4, pp. 1019-1033, 2016.

[46] K. Khosravi, H. Shahabi, B. T. Pham et al., "comparative assessment of flood susceptibility modeling using multi-criteria decision-making analysis and machine learning methods," Journal of Hydrology, vol. 573, pp. 311-323.

[47] O. Rahmati, H. Zeinivand, and M. Besharat, "Flood hazard zoning in Yasooj region, Iran, using GIS and multi-criteria decision analysis," Geomatics, Natural Hazards and Risk, vol. 7, no. 3, pp. 1000-1017, 2016 b.

[48] R. Termeh, S. Vahid, H. R. Pourghasemi, and F. Alidadganfard, "Flood inundation susceptibility mapping using analytical hierarchy process (AHP) and TOPSIS decision making methods and weight of evidence statistical model (case study: jahrom township, fars province)," Journal of Watershed Management Research, vol. 9, no. 17, pp. 67-81, $2018 \mathrm{a}$.

[49] M. Vojtek and J. Vojteková, "Flood susceptibility mapping on a national scale in Slovakia using the analytical hierarchy process," Water, vol. 11, no. 2, p. 364, 2019.
[50] D. Bin Ahmad, K. Khosravi, H. Shahabi et al., "spatial modeling in northern Iran using remote sensing and gis: a comparison between evidential belief functions and its ensemble with a multivariate logistic regression model," Remote Sensing, vol. 11, no. 13, p. 1589.

[51] A. S. Leon, E. A. Kanashiro, R. Valverde, and V. Sridhar, "Dynamic framework for intelligent control of river flooding: case study," Journal of Water Resources Planning and Management, vol. 140, no. 2, pp. 258-268, 2014.

[52] N. Haghipour, J.-P. Burg, F. Kober et al., "Rate of crustal shortening and non-Coulomb behaviour of an active accretionary wedge: the folded fluvial terraces in Makran (SE, Iran)," Earth and Planetary Science Letters, vol. 355-356, pp. 187-198, 2012.

[53] A. Reiesi and A. Kiani, The Status of Distributing Facilities and Services in Fanuj Based on Urban Smart Growth, 2018.

[54] Wikipedia, Fanuj City, Wikipedia, San Francisco, CA, USA, 2020b, https://www.sbportal.ir/fa/cities/fanouj.

[55] A. L. Kay, R. G. Jones, and N. S. Reynard, "RCM rainfall for UK flood frequency estimation. II. climate change results," Journal of Hydrology, vol. 318, no. 1-4, pp. 163-172, 2006.

[56] K. Li, S. Wu, E. Dai, and Z. Xu, "Flood loss analysis and quantitative risk assessment in China," Natural Hazards, vol. 63, no. 2, pp. 737-760, 2012.

[57] T. Nagler, H. Rott, M. Hetzenecker, J. Wuite, and P. Potin, "The Sentinel-1 mission: new opportunities for ice sheet observations," Remote Sensing, vol. 7, no. 7, pp. 9371-9389, 2015.

[58] D. Fernández and M. Lutz, "Urban flood hazard zoning in Tucumán Province, Argentina, using GIS and multicriteria decision analysis," Engineering Geology, vol. 111, no. 1-4, pp. 90-98, 2010.

[59] D. T. Bui, P.-T. T. Ngo, T. D. Pham et al., "A novel hybrid approach based on a swarm intelligence optimized extreme learning machine for flash flood susceptibility mapping," Catena, vol. 179, pp. 184-196, 2019.

[60] M. B. Cardenas, J. Wilson, and V. A. Zlotnik, "Impact of heterogeneity, bed forms, and stream curvature on subchannel hyporheic exchange," Water Resources Research, vol. 40 , no. $8,2004$.

[61] F. Falah, O. Rahmati, M. Rostami, E. Ahmadisharaf, I. N. Daliakopoulos, and H. R. Pourghasemi, "Artificial neural networks for flood susceptibility mapping in data-scarce urban areas," Spatial Modeling in GIS and R for Earth and Environmental Sciences, pp. 323-336, Elsevier, Amsterdam, Netherlands, 2019.

[62] F. Messner and V. Meyer, Flood Damage, Vulnerability and Risk Perception-Challenges for Flood Damage Research. Flood Risk Management: Hazards, Vulnerability and Mitigation Measures, pp. 149-167, Springer, Berlin, Germany, 2006.

[63] I. D. Moore, R. B. Grayson, and A. R. Ladson, "Digital terrain modelling: a review of hydrological, geomorphological, and biological applications," Hydrological Processes, vol. 5, no. 1, pp. 3-30, 1991.

[64] D. M. Barker, D. M. Lawler, D. W. Knight, D. G. Morris, H. N. Davies, and E. J. Stewart, "Longitudinal distributions of river flood power: the combined automated flood, elevation and stream power (CAFES) methodology," Earth Surface Processes and Landforms, vol. 34, no. 2, pp. 280-290, 2009.

[65] I. C. Fuller, "Geomorphic impacts of a 100-year flood: kiwitea stream, manawatu catchment, New Zealand," Geomorphology, vol. 98, no. 1-2, pp. 84-95, 2008.

[66] C. Gokceoglu, H. Sonmez, H. A. Nefeslioglu, T. Y. Duman, and T. Can, "The 17 March 2005 Kuzulu landslide (Sivas, 
Turkey) and landslide-susceptibility map of its near vicinity," Engineering Geology, vol. 81, no. 1, pp. 65-83, 2005.

[67] H. Hong, P. Tsangaratos, I. Ilia, J. Liu, A.-X. Zhu, and W. Chen, "Application of fuzzy weight of evidence and data mining techniques in construction of flood susceptibility map of Poyang County, China," Science of the Total Environment, vol. 625 , pp. $575-588,2018$ b.

[68] J. M. García-Ruiz, D. Regüés, B. Alvera et al., "Flood generation and sediment transport in experimental catchments affected by land use changes in the central Pyrenees," Journal of Hydrology, vol. 356, no. 1-2, pp. 245-260, 2008.

[69] E. P. Glenn, K. Morino, P. L. Nagler, R. S. Murray, S. Pearlstein, and K. R. Hultine, "Roles of saltcedar (Tamarix spp.) and capillary rise in salinizing a non-flooding terrace on a flow-regulated desert river," Journal of Arid Environments, vol. 79, pp. 56-65, 2012.

[70] R. Aalto, L. Maurice-Bourgoin, T. Dunne, D. R. Montgomery, C. A. Nittrouer, and J.-L. Guyot, "Episodic sediment accumulation on Amazonian flood plains influenced by El Niño/ Southern Oscillation," Nature, vol. 425, no. 6957, pp. 493-497, 2003.

[71] A. M. Prasad, L. R. Iverson, and A. Liaw, "Newer classification and regression tree techniques: bagging and random forests for ecological prediction," Ecosystems, vol. 9, no. 2, pp. 181-199, 2006.

[72] D. Geudtner, R. Torres, P. Snoeij, M. Davidson, and B. Rommen, Sentinel-1 System Capabilities and Applications, IEEE, in Proceedings of the 2014 IEEE Geoscience and Remote Sensing Symposium, pp. 1457-1460, IEEE, Québec City, Québec, Canada, July 2014.

[73] D. Shirzadi, H. Shahabi, A. Mohammadi, B. Bin Ahmad, M. Bin Jamal, and A. Ahmad, "Land cover change mapping using a combination of Sentinel-1 data and multispectral satellite imagery: a case study of Sanandaj county, Kurdistan, Iran," Applied Ecology and Environmental Research, vol. 17, no. 3, pp. 5449-5463, 2019 b.

[74] A. Mohammadi, B. Bin Ahmad, and H. Shahabi, "Extracting digital elevation model (DEM) from sentinel-1 satellite imagery: case study a part of Cameron highlands, Pahang, Malaysia," International Journal of Applied Management Science, vol. 4, pp. 109-114, 2018.

[75] Y. Freund and L. Mason, "The alternating decision tree learning algorithm,” Icml, vol. 99, pp. 124-133, 1999.

[76] H. K. Sok, M. P.-L. Ooi, and Y. C. Kuang, "Sparse alternating decision tree," Pattern Recognition Letters, vol. 60-61, pp. 57-64, 2015.

[77] W. Chen, X. Xie, J. Peng, J. Wang, Z. Duan, and H. Hong, "GIS-based landslide susceptibility modelling: a comparative assessment of kernel logistic regression, Naïve-Bayes tree, and alternating decision tree models," Geomatics, Natural Hazards and Risk, vol. 8, no. 2, pp. 950-973, 2017.

[78] L. Breiman, "Bagging predictors," Machine Learning, vol. 24, no. 2, pp. 123-140, 1996.

[79] B. Efron and R. J. Tibshirani, Cross-validation and the Bootstrap: Estimating the Error Rate of a Prediction Rule: Division of Biostatistics, Stanford University, Kunnamangalam, Kerala, India, 1995.

[80] Y. Piao, M. Piao, C. H. Jin et al., "A new ensemble method with feature space partitioning for high-dimensional data classification," Mathematical Problems in Engineering, vol. 2015, Article ID 590678, 12 pages, 2015.

[81] E. Bauer and R. Kohavi, "An empirical comparison of voting classification algorithms: bagging, boosting, and variants," Machine Learning, vol. 36, no. 1-2, pp. 105-139, 1999.
[82] Y. Wang, H. Hong, W. Chen et al., "A hybrid GIS multicriteria decision-making method for flood susceptibility mapping at Shangyou, China," Remote Sensing, vol. 11, no. 1, p. 62, 2019a.

[83] D. T. Bui, B. Pradhan, H. Nampak, Q.-T. Bui, Q.-A. Tran, and Q.-P. Nguyen, "Hybrid artificial intelligence approach based on neural fuzzy inference model and metaheuristic optimization for flood susceptibilitgy modeling in a high-frequency tropical cyclone area using GIS," Journal of Hydrology, vol. 540, pp. 317-330, 2016.

[84] A. Mohammadi, H. Shahabi, and B. Bin Ahmad, "Integration of insartechnique, google earth images and extensive field survey for landslide inventory in a part of Cameron highlands, Pahang, Malaysia," Applied Ecology and Environmental Research, vol. 16, pp. 8075-8091, 2007.

[85] B. T. Pham, I. Prakash, J. Dou et al., "A novel hybrid approach of landslide susceptibility modelling using rotation forest ensemble and different base classifiers," Geocarto International, pp. 1-25, 2019.

[86] K. Khosravi, E. Nohani, E. Maroufinia, and H. R. Pourghasemi, "A GIS-based flood susceptibility assessment and its mapping in Iran: a comparison between frequency ratio and weights-of-evidence bivariate statistical models with multi-criteria decision-making technique," Natural Hazards, vol. 83, no. 2, pp. 947-987, 2016.

[87] IRNA: 2020, https://www.irna.ir/news/83631974/.

[88] B. T. Pham, D. Tien Bui, and I. Prakash, "Landslide susceptibility assessment using bagging ensemble based alternating decision trees, logistic regression and J48 decision trees methods: a comparative study," Geotechnical and Geological Engineering, vol. 35, no. 6, pp. 2597-2611, 2017. 